\title{
Investigation on Seismic Behaviour of Masonry Infilled Self-Centring-Beam Moment-Frames using New Infill Material Model
}

\author{
Xiaogang Huang \\ Chongqing University \\ Zhen Zhou ( $\nabla$ seuhj@163.com ) \\ Southeast University \\ yuhang wang \\ Chongqing University
}

\section{Research Article}

Keywords: Self-centring beams, Hysteretic model, Reloading degradation, Seismic analysis, Finite element methods.

Posted Date: February 17th, 2021

DOl: https://doi.org/10.21203/rs.3.rs-176024/v1

License: (c) (i) This work is licensed under a Creative Commons Attribution 4.0 International License. Read Full License 


\title{
Investigation on Seismic Behaviour of Masonry Infilled Self-Centring-Beam Moment-Frames using New Infill Material Model
}

\author{
Xiaogang Huang ${ }^{1}$; Zhen Zhou $^{2 *}$; Yuhang Wang ${ }^{1}$ \\ 1. School of Civil Engineering, Chongqing University, Chongqing 400045, China. \\ 2. Key Laboratory of Concrete and Prestressed Concrete Structures of the Ministry of Education, Southeast University, \\ Nanjing 210096, China. E-mail: seuhj@163.com.
}

\begin{abstract}
This paper conducted experimental and numerical investigations on seismic behaviour of masonry infilled selfcentring-beam moment-frames (SCB-MFs). First, an efficient hysteretic material model was proposed for use with the equivalent strut modelling approach of infill walls. This model was defined by backbone parameters and hysteretic parameters and implemented in the OpenSees platform to facilitate its application. Then, an approximately half-scale test of infilled SCB-MFs was carried out. The test observations and load-carrying capacities of masonry walls in the specimen were reported and analysed. The experimental hysteresis was reproduced by the numerical model using the proposed infill material. Finally, structural analyses were conducted for 3-, 6-, 9-, and 12-storey infilled SCB-MFs based on the calibrated computational model. Comparisons of the hysteretic behaviours obtained by the simulation with experimental results showed that the proposed infill material could capture the strength, stiffness, and energy dissipation during reloading, along with the residual drift during unloading. The nonlinear dynamic analyses also validated the feasibility of using the proposed model to simulate the dynamic responses of infilled SCB-MFs.
\end{abstract}

keywords: Self-centring beams; Hysteretic model; Reloading degradation; Seismic analysis; Finite element methods.

\section{Introduction}

Masonry infill walls are widely used as non-structural partitions in earthquake-resisting frames because of their low material and fabrication costs, as well as their good sound and heat insulation properties. However, frame-infill interaction has seemed apparent in past earthquakes (Li et al. 2008; Fikri et al. 2019), which can induce unexpected seismic behaviours. Infill walls are typically constructed using solid bricks and wet mortar. Their anisotropic and nonhomogeneous material composition complicates the hysteretic behaviours of infill walls. The failure modes of infill walls in moment-frames (MFs) are usually categorised into four groups (Mehrabi et al. 1996; El-Dakhakhni et al. 2003; Colangelo et al. 2013; Chiozzi et al. 2017; Wang et al. 2019) at present: siding shear failure, diagonal cracking failure; diagonal compression failure, and corner crushing failure.

The earthquake damage to infill walls is influenced by the confinement effect resulting from the contact region of the surrounding frame, excepting for the relevance with infill material properties. The current focus of most research is on the hysteretic behaviours of infill walls in traditional frames with fully welded connections. Moment connections using post-tensioning concepts have recently been developed to ensure self-centring capacities in frames during earthquake loading. Unlike welded connections, the most obvious characteristic of post-tensioning connections is their relative rotation between beams and columns. The rotation provides a deformation capacity for the gap-openingclosing mechanism (Ricles et al. 2001; Garlock et al. 2005; Dimopoulos et al. 2013; Clayton et al. 2013; Huang et al. 2017; Fang et al. 2017; Li et al. 2020) and changes the frame-infill contact. Previous experiments have suggested that 
hysteretic responses of infill walls in frames with pinned connections (Moghadam et al. 2006; Lin et al. 2019) are different from those in frames with welded connections. Therefore, the failure modes of infill walls in self-centring frames should be further investigated.

Single diagonal strut modelling approach first developed by Polyakov (1994) provides a simplified simulation of in-plane behaviours of infill walls on frames without compromising numerical accuracy. Numerous phenomenological models have been proposed to describe the mechanical properties of the equivalent strut using simple mathematical equations. Klingner et al. (1978), Panagiotakos and Fardis (1994), Cavaleri et al. (2014), and Liberatore (2001) proposed different hysteretic models to account for the actual pinching behaviours of the infill walls, which would be thoroughly compared in the following section. FEMA356 (2000), Al-Chaar (2002), Mostafaei and Kabeyasawa (2004) and Liberatore et al. (2018) developed different force-displacement envelope models for the equivalent strut, but did not define the unloading and reloading branches. Recently, many researchers (Celarec et al. 2012; Martinelli et al. 2015; Jeon et al. 2015; Mohammad et al. 2016; Landi et al. 2016; Noh et al. 2017; Huang et al. 2018a, 2018b; Skoulidou et al. 2019a, 2019b) have simulated the behaviour of infill walls with the help of some existing materials available in the OpenSees software, such as the Hysteretic and Concrete01 materials. Most of these approaches could capture the backbone curves of infill walls, but failed to accurately account for the hysteretic responses of the infill walls under cyclic loading.

To avoid these effects in analysing hysteretic responses of masonry infilled self-centring-beam moment-frames (SCB-MFs), a new phenomenological model is proposed in this paper that can accurately reproduce the hysteretic behaviours of infill walls in different types of frames. This one-dimensional material model has been implemented in the OpenSees platform to facilitate its application. The reloading degradation is controlled by the RahnamaKrawinkler cyclic deterioration rules (Rahnama and Krawinkler, 1993). The reloading path is described by the Menegotto-Pinto formulation (Menegotto, 1973). Based on the new understanding on infill walls, the frame-infill interaction in the SCB-MFs was analysed by conducting experimental and numerical investigations. Finally, a nonlinear time-history analysis was performed based on the proposed model to analyse the effects of infill walls on the seismic responses of 3-, 6-, 9-, and 12-storey SCB-MFs under a set of 20 ground motions.

\section{Existing phenomenological models of infill walls}

The accuracy of single strut model largely depends on the adopted phenomenological material models, which usually include a piecewise linear backbone curve and hysteretic deterioration rules. This simplified macromodel cannot capture the local phenomena of infill walls but can be used for an analysis of infilled structures with superior numerical stability and computational efficiency. Figure 1 shows the typical materials employed in the current research to substitute for the stiffness and strength of infill walls. Panagiotakos and Fardis (1994) built interstory shear forcedrift relationship for the infill panel and applied it into the response analyses of the SDOF infilled frame. This model was usually adopted to define the force-displacement envelope of infill walls. However, the unloading and reloading rule of this model was symmetric in both directions and not applicable for single compression-only strut. Klingner $e t$ al. (1978) developed the first hysteretic modelling approach for nonlinear behaviours of the equivalent strut. Cavaleri et al. (2014) simplified a pivot material model and used a fundamental pivot point to consider the unloading stiffness deterioration of the equivalent strut. Liberatore (2001) introduced two parameters in the material model to reflect the degradation of the unloading and reloading branches of the equivalent strut. The characteristics of these models are

summarised from several important perspectives in this section, including the backbone curve, reloading stiffness and strength, and unloading stiffness. 
The backbone curve represents the monotonic responses of infill walls, which must have zero tensile strength because of the compression-only force transfer between the infill walls and frames. The envelope of the Klingner model had an elastic branch followed by an exponential curve, which provided limited user input options. The compression-side envelopes in the Cavaleri and Liberatore models were defined by a multi-linear curve comprised of different characteristic points. These parameters could have different values. Other researchers (Celarec et al. 2012; Martinelli et al. 2015; Jeon et al. 2015; Mohammad et al. 2016; Landi et al. 2016; Noh et al. 2017; Huang et al. 2018a, 2018b; Skoulidou et al. 2019a, 2019b) adopted the uniaxial material models available in the OpenSees software to model the hysteretic response of infill walls. The strength of the Hysteretic material in a positive direction was input as the minimum value to represent the negligible tensile strength of the infill walls to bounding frames. However, the Hysteretic material could not achieve compression-only behaviours under this condition because the reloading branch begins in the positive direction. The tensile frame-infill interaction affected the numerical accuracy when the loading was reversed in the positive direction. Huang et al. (2018b) proposed a series of materials that included the Hysteretic material and Elastic-no tension (ENT) material to model the compression-only behaviours of infill walls, in which the reloading branch occurred only when the strut was loaded to the maximum unloading point in history.

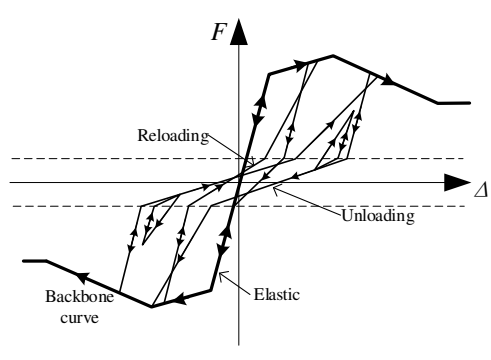

(a) Panagiotakos and Fardis

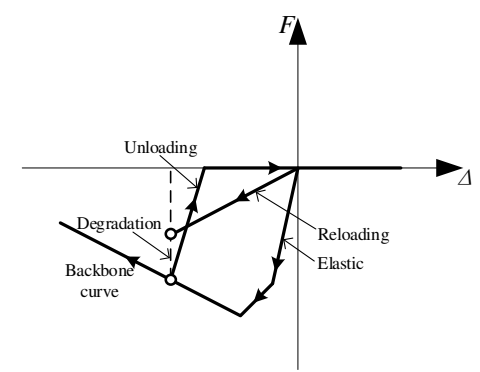

(d) Liberatore

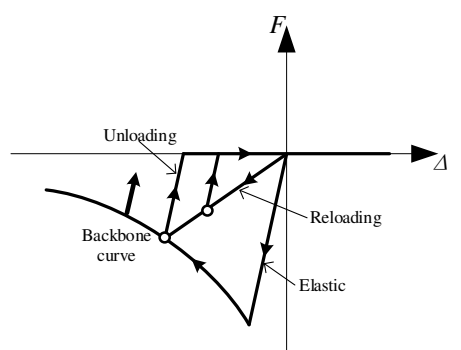

(b) Klingner et al.

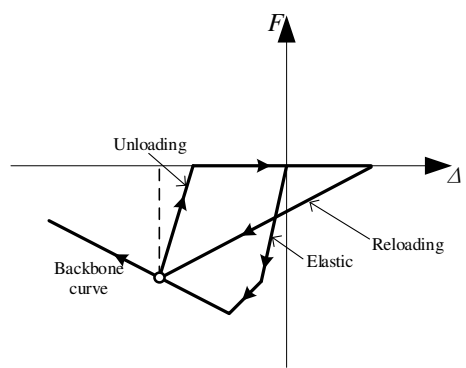

(e) Hysteretic material

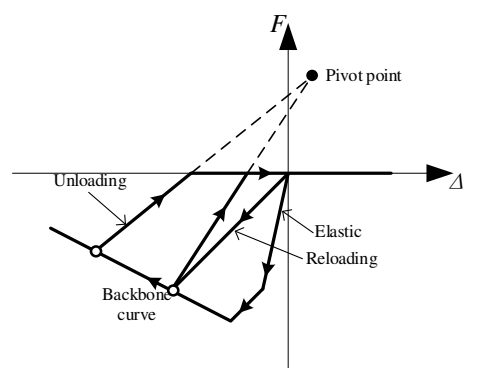

(c) Cavaleri et al.

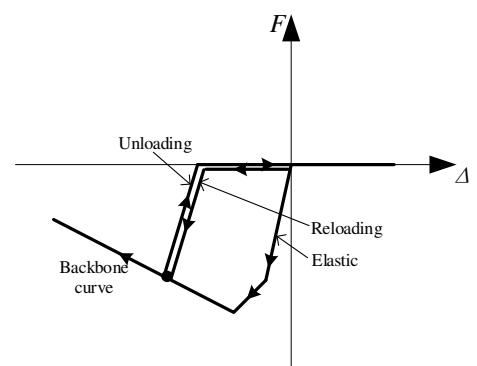

(f) Hysteretic+ENT material

Figure 1 Existing phenomenological models of infill walls

The reloading stiffness and strength of infill walls deteriorate with increases in the amplitude and number of cycles after the elastic branch is exceeded. The Klingner model considered the stiffness degradation in the linear reloading branch but did not include the effects of cyclic strength degradation. The Cavaleri model used a reloading branch similar to the Klingner model. In order to reflect the real deterioration of the reloading stiffness and strength, the Liberatore model also adopted a linear branch for the reloading degradation as a function of the cyclic dissipated energy. The Hysteretic $+E N T$ material assumed that the unloading and subsequent reloading followed the same line. This resulted in that the strength degradation occurring at every other cycle of the constant displacement amplitude could not be simulated. 
Infill walls provide no lateral contribution when they and the surrounding frames are detached from each other, leading to a very large unloading stiffness. The Klingner model assumed that the unloading was linear with a stiffness equal to the initial stiffness. The Cavaleri and Liberatore models thought cyclic degradation could occur in the unloading branch. The unloading degradation also existed when employing the Hysteretic material to simulate infill walls. The inaccuracy of the unloading stiffness may affect modelling residual drifts of the buildings.

\section{Proposed phenomenological hysteretic models for infill walls}

In this section, an efficient phenomenological hysteretic model was developed for the equivalent struts of infill walls, which retained the piecewise linear backbone curve of the previous model, and could capture the continuous change in the reloading stiffness related to the continuum nature of the panels and the degradation of the reloading strength associated with the amplitude and number of cycles. A new material called Infillo1 was accordingly added to the OpenSees platform using the $\mathrm{C}++$ language.

Figure 2 illustrates the characteristic of the Infillo1 material, in which the tension side is set to zero. There are four states for the compression side: State 1, State 2, State 3, and State 4. State 1 represents the material being loaded in the way that follows the backbone negative branch. The backbone curve is defined by three characteristic points. State 2 is the unloading branch where the unloading stiffness is the same as the initial one. To make the model applicable to arbitrary loading, the reloading case is divided into two scenarios. When the force is reduced to zero, the reloading occurs using State 3, where the pinching and degradation behaviours are considered. When the force is not reduced to zero, the reloading occurs using State 4, where the reloading and previous unloading follow the same line.

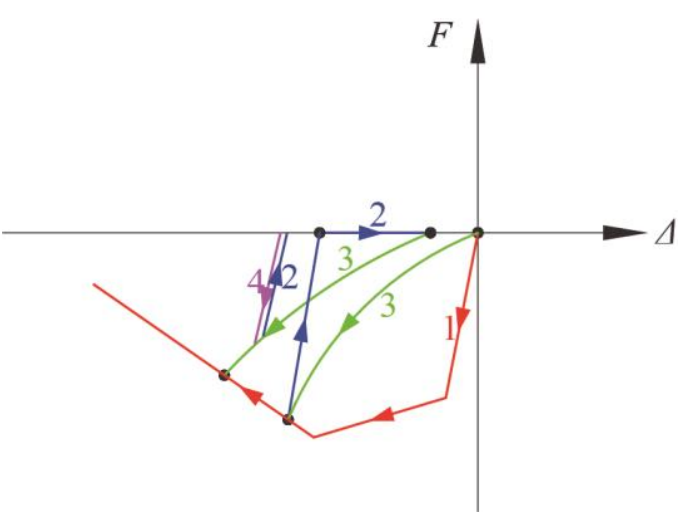

Figure 2 Infillo1 material states

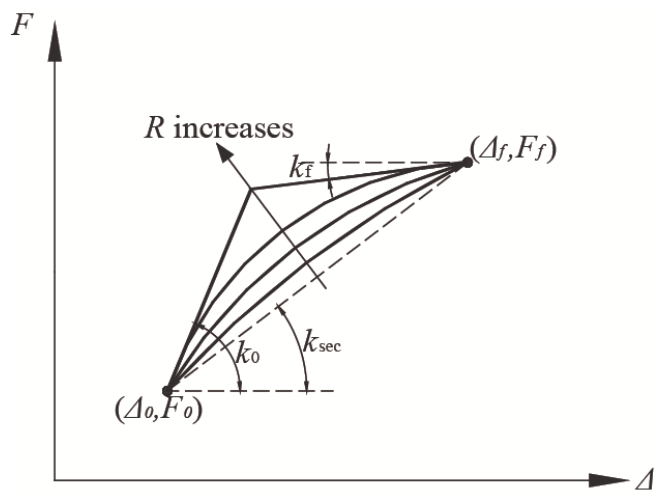

Figure 3 Illustration of Menegotto-Pinto equation

The Menegotto-Pinto (M-P) equation (Menegotto 1973) is adopted to provide a reasonable approximation of the infill resistance during reloading, which is suitable for describing a curve where the tangents at the two ends are known, as shown in Figure 3. The M-P equation is expressed as follows:

$$
\begin{aligned}
& F_{\mathrm{s}}=F_{0}+k_{0}\left(\Delta_{\mathrm{s}}-\Delta_{0}\right)\left\{Q+\frac{1-Q}{A}\right\} \\
& A=\left[1+\left|k_{0} \frac{\Delta_{\mathrm{s}}-\Delta_{0}}{F_{\mathrm{ch}}-F_{0}}\right|^{R}\right]^{\frac{1}{R}}
\end{aligned}
$$

where $\Delta_{\mathrm{s}}$ and $F_{\mathrm{s}}$ are the deformation and force at any point of the curve, respectively. The corresponding tangent 
modulus of this point is determined as follows:

$$
k_{\mathrm{s}}=k_{\mathrm{sec}}-\frac{k_{\mathrm{sec}}-Q k_{0}}{1+\left|k_{0} \frac{\Delta_{s}-\Delta_{0}}{F_{\mathrm{ch}}-F_{0}}\right|^{-R}}
$$

where $\Delta_{0}, F_{0}$, and $k_{0}$ are the deformation, force, and tangent modulus of the starting point, respectively; and $\Delta_{\mathrm{f}}, F_{\mathrm{f}}$, and $k_{\mathrm{f}}$ are the deformation, force, and tangent modulus of the ending point, respectively. The starting point is fixed at the backbone curve of the material, and the ending point is defined as the first reloading in the negative branch. The shape of the curve is controlled by parameter $Q, R$, and $F_{\mathrm{ch}}$, where $Q$ is the ratio of the ending tangent to the starting tangent. An increase in $R$ can increase the curvature of the curve. When $R=\infty$, the curve becomes two linear lines with tangents $k_{0}$ and $k_{\mathrm{f}} . F_{\mathrm{ch}}$ is the force at the intersection point of these two tangents, which is expressed as follows:

$$
\begin{gathered}
F_{\mathrm{ch}}=F_{0}+k_{0}\left(\Delta_{\mathrm{f}}-\Delta_{0}\right)\left\{\frac{a}{\left[1-a^{R}\right]^{\frac{1}{R}}}\right\} \\
a=\frac{Q-\frac{k_{\mathrm{sec}}}{k_{0}}}{Q-1}
\end{gathered}
$$

when $\Delta=\Delta_{\mathrm{f}}, a=A^{-1}$. The secant stiffness, $k_{\mathrm{sec}}$, between the starting point and the ending point of the reloading branch is calculated as follows:

$$
k_{\mathrm{sec}}=\frac{F_{\mathrm{f}}-F_{0}}{\Delta_{\mathrm{f}}-\Delta_{0}}
$$

If parameter $R$ is smaller than a critical value, $R_{\min }$, the reloading branch cannot reach the final point with predefined stiffness $k_{\mathrm{f}}$. Factor $R_{\min }$ is derived as follows:

$$
R_{\mathrm{min}}=\frac{k_{\mathrm{f}}-k_{\mathrm{sec}}}{k_{\mathrm{sec}}-k_{0}}
$$

To avoid this limiting case of the M-P equation, the reloading branch is defined to be linear once a value of $R<$ $R_{\min }$ is input to the material by the user.

Previous experiments have suggested that infill walls experience reloading degradation in the strength and stiffness under cyclic loading. This phenomenon can be characterised by the cyclic deterioration rule given by Rahnama and Krawinkler (1993), which utilises a predefined reference capacity to represent the total hysteretic energy dissipation of the material. The cyclic deterioration, $\beta_{\mathrm{i}}$, of the material is expressed as follows:

$$
\begin{aligned}
& \beta_{i}=\left(\frac{E_{i}}{E_{\mathrm{t}}-\sum_{j=1}^{i} E_{j}}\right)^{g k 2} \\
& E_{\mathrm{t}}=\left(g k_{1}\right) F_{\mathrm{y}} \delta_{\mathrm{y}}
\end{aligned}
$$

where $E_{\mathrm{i}}$ is the dissipated hysteretic energy of the $i_{\mathrm{th}}$ cycle. $\Sigma E_{\mathrm{j}}$ is the summation of the dissipated hysteretic energy in all of the previous loading cycles. $E_{\mathrm{t}}$ is the total reference hysteretic energy capacity, a value of one is adopted for $\delta_{\mathrm{y}}$ to facilitate the calculation of $E_{\mathrm{t}}$, and $F_{\mathrm{y}}$ is the yielding strength of the material. Parameters $g k_{1}$ and $g k_{2}$ can be calibrated using the experimental results. Parameter $\beta_{\mathrm{i}}$ is refreshed each time the unloading branch crosses the horizontal axis.

The energy dissipation, $\mathrm{d} E$, of the material at each incremental step is calculated as follows: 


$$
\mathrm{d} E=0.5\left(F_{j}+F_{j-1}\right) \mathrm{d} \Delta
$$

where $F_{\mathrm{j}}$ is the material force at the current step, $F_{\mathrm{j}-1}$ is the material force at the last step, and $d \Delta$ is the material deformation difference between adjacent steps.

The degradation in the reloading stiffness of the material can be found as follows:

$$
K_{\mathrm{r}, i}=\left(1-\beta_{i}\right) K_{\mathrm{r}, i-1}
$$

where $K_{\mathrm{r}, i}$ and $K_{\mathrm{r}, i-1}$ are the reloading stiffness values of the material at the $i_{\mathrm{th}}$ and $i-1_{\mathrm{th}}$ cycles, respectively.

The Infill01 material, defined by backbone parameters and hysteretic parameters, has been implemented in the OpenSees software. The backbone parameters can be input based on the force-displacement relationship developed by Panagiotakos and Fardis (1994). The envelope model has shown good accuracy and been widely adopted

in previous predictions (Celarec et al. 2012; Jeon et al. 2015; Mohammad et al. 2016; Huang et al. 2018b). The hysteretic is determined by five parameters. Parameters $g k_{1}$ and $g k_{2}$ control the cyclic deterioration rate of the reloading stiffness. Parameters beta, $Q$ and $R$ control the curvature variation in the reloading shape. Parameter beta is the ratio of starting tangent $k_{0}$ to secant stiffness $k_{\text {sec. }}$. The other reloading parameters $\left(g k_{1}, g k_{2}, Q\right.$, and $\left.R\right)$ were defined in the previous paragraph.

A truss element assigned the Infillo1 material was modelled to illustrate the proposed degradation path. One end was restrained at degrees-of-freedom UX and UY, whereas the other end was only restrained at UY and allowed cyclic displacement at UX. The displacement protocol was performed twice consecutively and consisted of one cycle of symmetric amplitudes of $0.375,0.5,0.75,1.0,1.5,2.0$, and 3.0\%. Figure 4 shows the parametric analysis results for the element, which had a compression-only load-displacement response. The reloading parameters used in each analysis are listed in the figure. If $R$ is set to zero in Figure 4(a), the reloading branch is a linear line. If $R$ is increased to 10.0 in Figure 4(b), the reloading branch becomes a curve with a variable radius of curvature. If $R$ is further increased to 100.0 in Figure 4(c), the reloading branch is transformed into a piecewise line. Moreover, two loading runs exhibit similar curvature transition rules with the variation of $R$, but there is obvious degradation in the reloading behaviours of the second run.
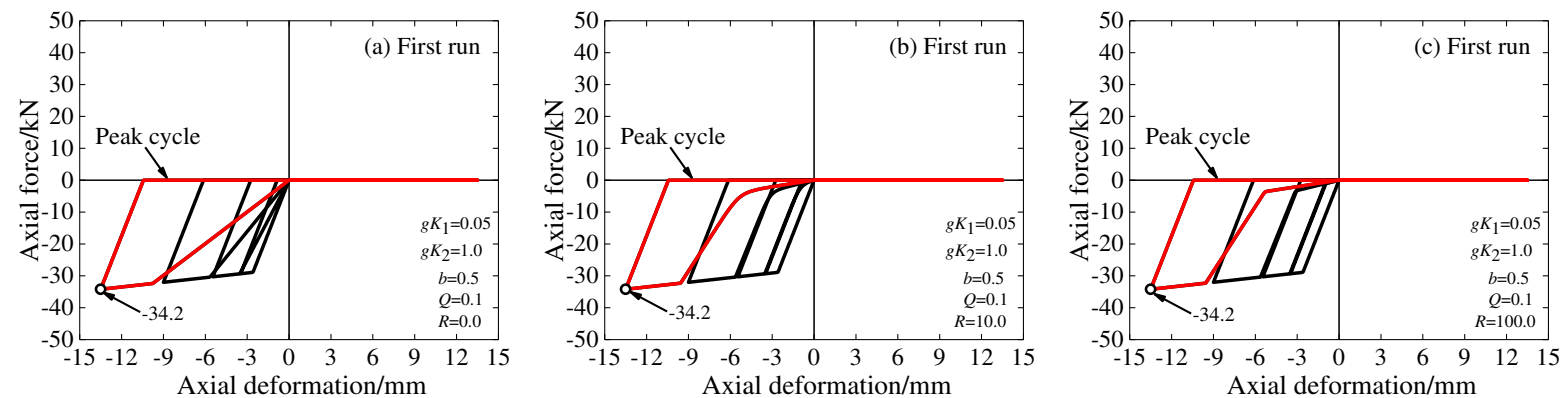

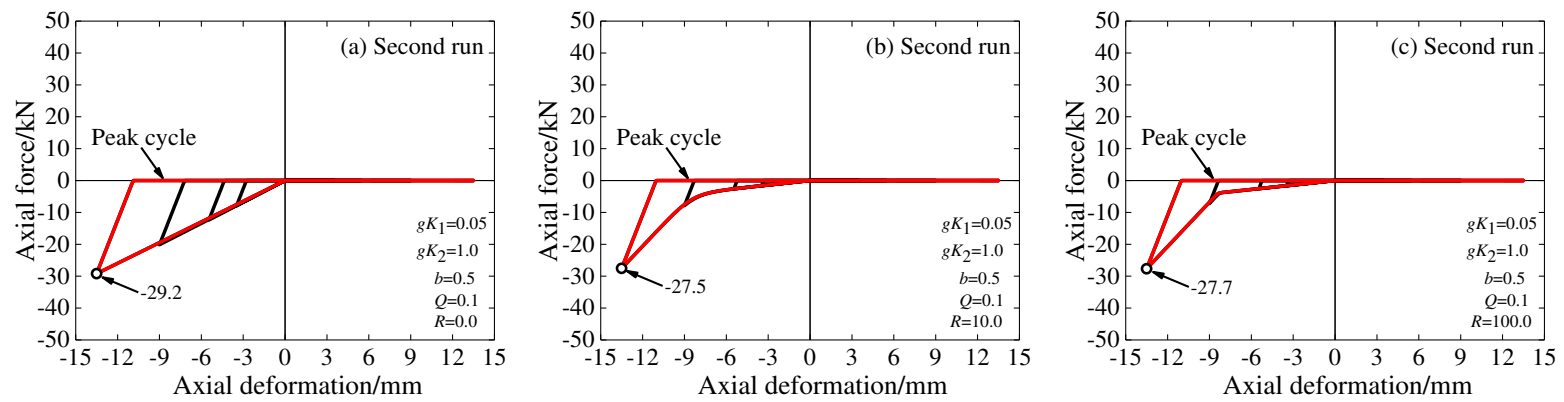

Figure 4 Parametric analysis results for Infillo1 material: (a) $R=0.0$, (b) $R=10.0$, and (c) $R=100.0$

\section{Experimental calibration of hysteretic model}

The hysteretic parameters of the Infill01 material needed to be calibrated using a comparison of three different groups of experimental results. The experimental data were extracted as discrete points by the pixel of the image in the literature. Similar extraction was also used in other research (Laura et al. 2018) to validate their simulations. The two-dimensional numerical models of different specimens were created in the OpenSees software. The masonry infill walls were represented by a pin-jointed equivalent diagonal strut. The calibration was conducted using iterative calculations of the material parameters with the objective of achieving a best match between the hysteretic responses of the simulation and experiment.

\subsection{Modelling of infilled steel frames}

Tasnimi and Mohebkhah (2011) analysed the hysteretic responses of steel MFs with clay brick masonry infill walls having openings. The beams and columns of all the specimens were sized like an IPE140 section. The height, length, and thickness of the infill walls were 1800,2260 , and $110 \mathrm{~mm}$, respectively. The average compressive strength of a masonry prism made of three $219 \times 110 \times 66 \mathrm{~mm}$ solid clay bricks was $7.63 \mathrm{MPa}$. The loading displacement protocol was comprised of one cycle of symmetric storey drifts with amplitudes equal to $25 \%, 50 \%, 75 \%$, etc. of the predicted yield displacement. The experimental results for specimen BF, specimen SW, and specimen PW1 were chosen to validate the proposed hysteretic model. Specimen BF was designed as a bare frame without any infill walls. Specimen SW was designed as a uniformly infilled frame without any opening. Specimen PW1 was identical to SW except that it had a $500 \times 500 \mathrm{~mm}$ concentric window opening.

Table 1 lists the calibrated values of the Infill01 material parameters for two infilled specimens. The first three parameters, $E_{\mathrm{d}}, f_{\mathrm{d}}$, and $n$, were used to define the material envelope in the Panagiotakos model, where $E_{\mathrm{d}}$ and $f_{\mathrm{d}}$ represent the Young's modulus and cracking strength of the masonry prisms along the diagonal direction. Parameter $n$ is the ratio of the deformation corresponding at residual strength $V_{\mathrm{r}}$ to the deformation corresponding at peak strength $V_{\mathrm{p}}$, representing the degradation rate of the infill walls after capping. The existence of the central opening caused a decrease in the lateral strength of the infill walls. The presence of the openings in the infill walls was considered in the model using a factor of 0.91 to reduce diagonal cracking strength $f_{\text {d. }}$. Moreover, parameter $n$ and $g k_{2}$ in specimen PW1 were $42.9 \%$ and $16.7 \%$ lower than those in specimen SW, showing a significant reduction in the ductile response of the infill walls. The simulated response of each model is compared with the experimental results in Figure 5. The modelling of the bare frame was validated by the experimental results for specimen BF, as shown in Figure 5(a). The simulated hysteretic responses of the infilled specimens in Figure 5(b) and (c) suggested that the simulation provided reasonable estimations of the reloading and unloading paths of the infill walls. Moreover, the residual drift was captured for the two infilled specimens because there was no infill-induced shear failure in the steel frames. 
Table 1. Calibrated Infill01 material parameters for specimens by Tasnimi

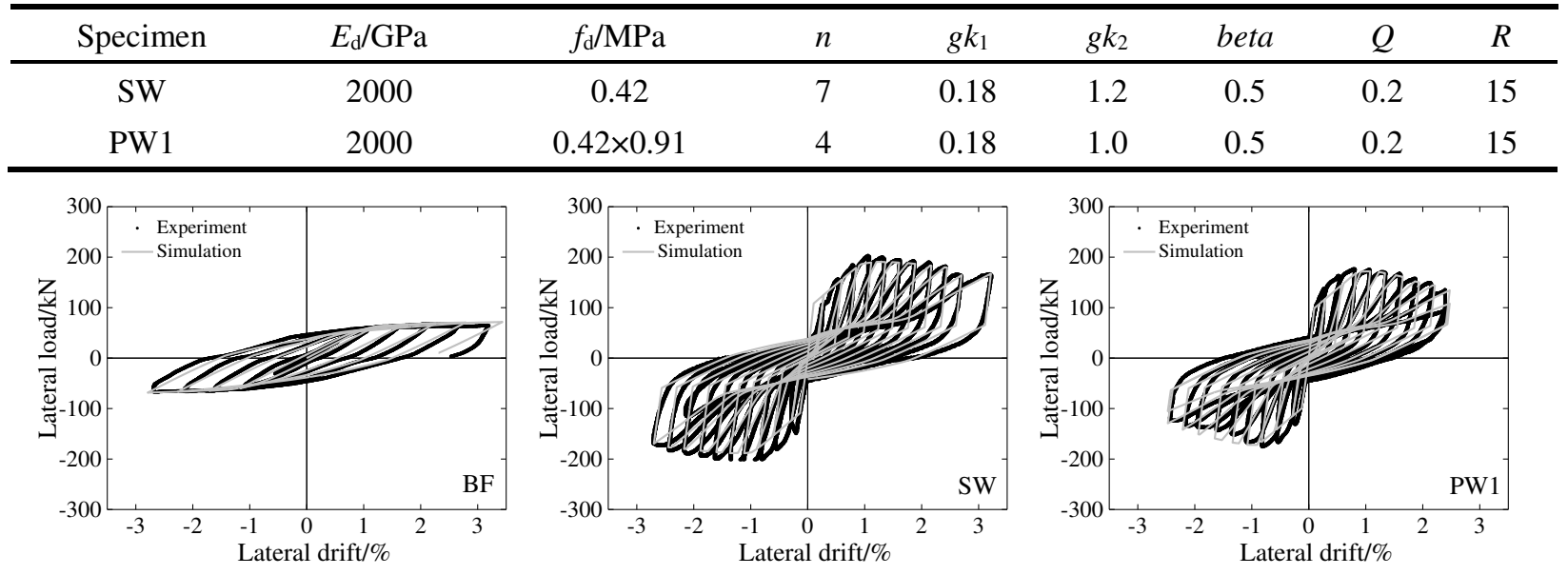

Figure 5 Hysteretic responses of infilled steel moment frame tested by Tasnimi: (a) BF, (b) SW, and (c) PW1

\subsection{Modelling of infilled concrete frames}

Alwashali et al. (2019) investigated the hysteretic responses of concrete MFs with masonry infill walls. The experimental results of specimen WB, specimen F-0.6, and specimen WM were chosen to validate the proposed hysteretic model. The column cross sections of all the specimens were $200 \times 200 \mathrm{~mm}, 4 \Phi 16$ bars were used as the longitudinal reinforcements, and $\Phi 6$ bars at $100 \mathrm{~mm}$ intervals were used as stirrups. The strong-column/weak-beam requirements were adopted for specimen WB (the ratio of the beam to column's flexural moment capacity $M_{\mathrm{ub}} / M_{\mathrm{uc}}=$ 0.7 ). The beam cross section was $200 \times 250 \mathrm{~mm}$, with $6 \Phi 13$ longitudinal bars. An infill wall made of $210 \times 100 \times 60 \mathrm{~mm}$ bricks had a height of $1475 \mathrm{~mm}$ and length of $2100 \mathrm{~mm}$. The average compressive strengths of a single brick and the mortar were 38.1 MPa and 27.7 MPa, respectively. Two parameters were analysed for the other specimens: the beam strength of the bounding frame for specimen F-0.6 and the mortar strength of the infill wall for specimen WM. To reflect strong beams and weaker columns in old buildings, the beam in specimen F- 0.6 was designed to have a cross section of $600 \times 400 \mathrm{~mm}$, with $10 \Phi 22$ longitudinal bars. Specimen WM was identical to specimen F-0.6, except it was constructed with a compressive mortar strength of $4.8 \mathrm{MPa}$.

The beams and columns were modelled by nonlinearBeamColumn elements. The concrete and reinforcing steel were modelled by the Concrete 22 material and Steel02 material, respectively. The material parameters of the confined concrete were calculated using the approaches proposed by Mander et al. (1988) Table 2 lists the calibrated values of the Infill01 material parameters based on tests. Parameters $n$ and $g k 1$ were increased by $150 \%$ and $250 \%$, respectively, after the beam yield moment was increased by $842.9 \%$ from specimen WB to specimen F-0.6. This showed that a more ductile response for the infill walls was achieved when the hinge location was shifted from the beam ends to column ends. Moreover, there was a slight variation in the material parameters of specimens F-0.6 and WM, suggesting that the reduced mortar strength had a slight influence on the hysteretic behaviours of the infill walls. The results of the numerical model are compared with the experimental results in Figure 6 to investigate their accuracy. A good performance was achieved in the simulation of the cyclic degradation of the reloading strength and stiffness under a constant displacement amplitude. However, the simulation could not accurately capture the residual drift during unloading, particularly in specimens F-0.6 and WM. This may be attributable to two effects: (1) the fibre-based element used for frame members was not capable of representing the shear cracks in columns observed in the experiments, and (2) the shear forces in the frame members were not replicated using the single equivalent strut model. 
Specimen WB experienced less shear damage to frame members in the experiment, and therefore its residual drift was reproduced more accurately in the simulation compared to the other specimens.

Table 2. Calibrated Infillo1 material parameters for specimens by Alwashali

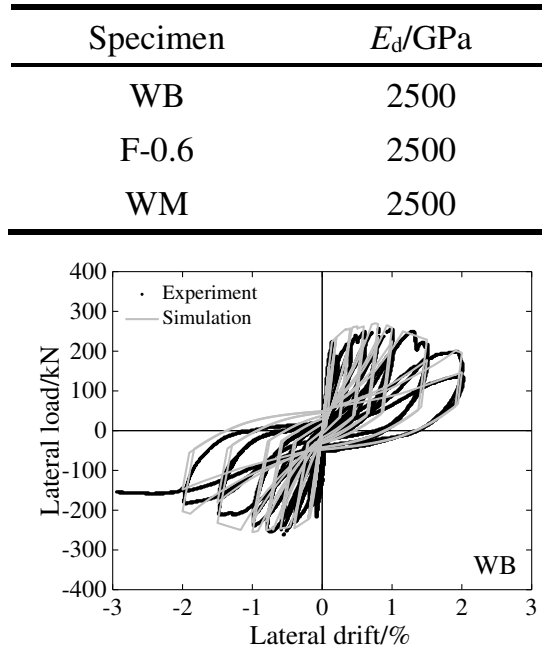

\begin{tabular}{ccc}
$f_{\mathrm{d}} / \mathrm{MPa}$ & $n$ & $g k_{1}$ \\
\hline 0.85 & 4 & 0.12 \\
0.85 & 6 & 0.3 \\
0.85 & 6 & 0.25 \\
\hline 400 & & \\
\hline . Experiment & & \\
\hline & & \\
\hline
\end{tabular}

$\begin{array}{cccc}g k_{2} & \text { beta } & Q & R \\ 1.0 & 0.5 & 0.2 & 1 \\ 1.1 & 0.5 & 0.2 & 1 \\ 1.1 & 0.5 & 0.3 & 1\end{array}$

Figure 6 Hysteretic response of infilled concrete moment frame tested by Alwashali: (a) WB, (b) F-0.5, and (c) WM

\subsection{Modelling of infilled pinned frames}

Lin (2019) investigated the hysteretic behaviours of pinned frames combined with different kinds of masonry infill walls. The true pin connection in the joints allowed free rotation between the beams and columns. The height and length of the infill walls were 2450 and $3350 \mathrm{~mm}$, respectively. Specimen IW1 was infilled with A5.0 autoclaved aerated concrete (AAC) masonry, with the dimensions of $600 \mathrm{~mm} \times 200 \mathrm{~mm} \times 200 \mathrm{~mm}$. Specimen IW2 was infilled with MU10 perforated concrete (PC) masonry, with the dimensions of $230 \mathrm{~mm} \times 170 \mathrm{~mm} \times 70 \mathrm{~mm}$. The specimens were mainly tested using three cycles of amplitudes $(1 / 200,1 / 150,1 / 100,1 / 50,1 / 35$, and 1/25) after smaller loading cycles.

The beams and columns of specimens IW1 and IW2 were modelled by nonlinearBeamColumn elements assigned the Steel02 material. The pinned connections were modelled using the equalDOF command to achieve pure in-plane translation, but there was no rotation constraint between the beams and columns. The calibrated material parameter values for the two specimens are presented in Table 3. There was no stiffness and strength degradation in the envelope curve of specimen IW1 during the entire loading. Therefore, parameter $n$ was not used for the model. The AAC masonry infill walls had a lower strength, but a greater ductile deformation capacity compared to the PC masonry infill walls. It could be seen that diagonal cracking strength $f_{\mathrm{d}}$ of specimen IW 2 was 7 times that of specimen IW1, but parameters $g k_{1}$ and $R$ in specimen IW2 were $50.0 \%$ and $66.7 \%$ lower than those in specimen IW1, respectively. The analytically obtained hysteretic responses are compared with the experimental results in Figure 7. Specimen IW2 experienced local crushing of the infill walls because of the $35 \%$ hollow ratio of a single block. Therefore, a strength degradation was observed in the envelope curve of specimen IW2. The simulation could accurately capture the reloading strength degradation under a constant displacement amplitude, along with the continuum nature of the reloading stiffness. The modelling errors were mainly caused by the asymmetrical responses in the two opposite loading directions.

Table 3. Calibrated Infillo1 material parameters for specimens by Lin 


\begin{tabular}{ccccccccc}
\hline Specimen & $E_{\mathrm{d}} / \mathrm{GPa}$ & $f_{\mathrm{d}} / \mathrm{MPa}$ & $n$ & $g k_{1}$ & $g k_{2}$ & beta & $Q$ & $R$ \\
\hline IW1 & 200 & 0.1 & - & 0.3 & 1.2 & 0.5 & 0.2 & 9 \\
IW 2 & 2000 & 0.7 & 3 & 0.15 & 1.0 & 0.5 & 0.2 & 3 \\
\hline
\end{tabular}
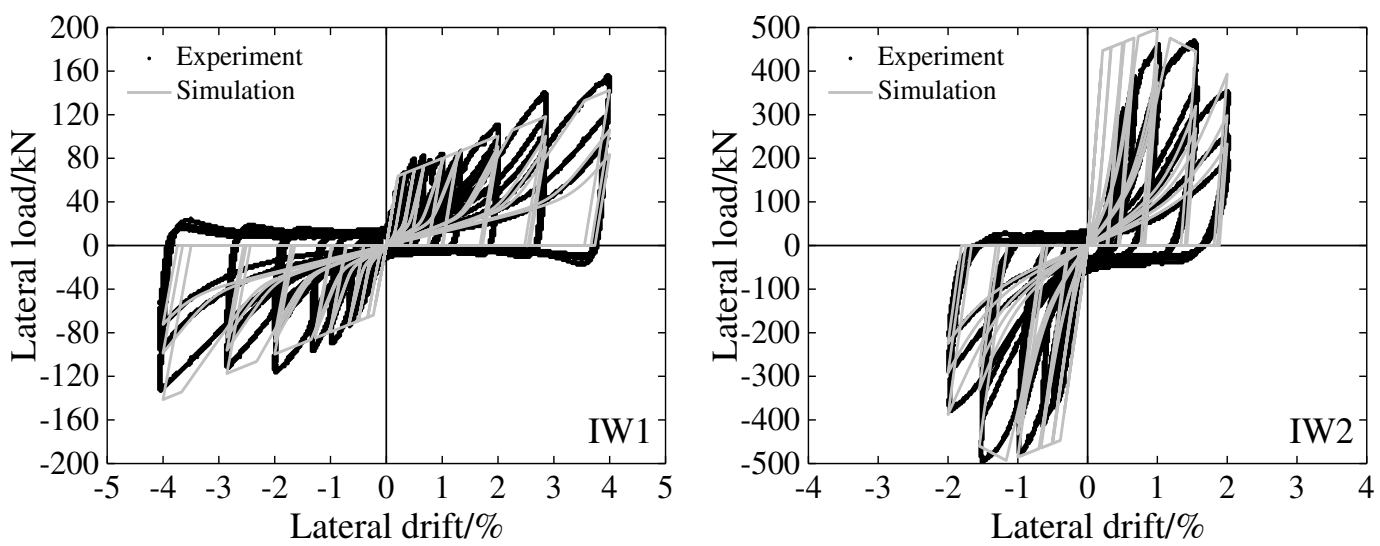

Figure 7 Hysteretic responses of infilled pinned frame tested by Yang: (a) IW1 and (b) IW2

A comparison of the calibrated hysteretic parameters showed that parameters $g k_{2}$, beta, and $Q$ could be regarded as approximately constant. The modelling responses were more sensitive to the variation of parameter $g k_{1}$, which controlled the total hysteretic dissipation, and parameter $R$, which controlled the reloading shape. These two parameters were calibrated using different values for the different specimens because of the great variability in the masonry materials and boundary conditions of the infill walls. However, the above calibration for the three different groups of infilled frames will provide a reference for the two parameters in future simulations.

From the above, the failure mechanism of infill walls is related not only to the material properties of the brick and mortar, but also to the interaction with the bounding frame. After traditional MFs are loaded laterally, the deflected shapes of the beams and columns lead to the separation of the infill wall and frame, but a corner contact region on the infill wall is caused by the bearing action of rigid beam-column connections, producing an equivalent diagonal strut mechanism for the bounding frame. The concentrated effect easily induces the corner crushing of the infill wall, which prevents it from rapidly carrying a greater load. Accordingly, the common failure modes in traditional MFs are corner crushing and diagonal cracking, as shown in Figure 8(a). For infill walls in pinned frames under lateral loading, the beams experience a horizontal motion after the columns are deformed. The relative rotation of the pinned beamcolumn connections cannot provide enough confinement for the corner of the infill wall. The bearing action between the columns and infill wall has a larger contact region along the column body, which produces an uncommon failure mode that appears as widespread cracking, as shown in Figure 8(b).
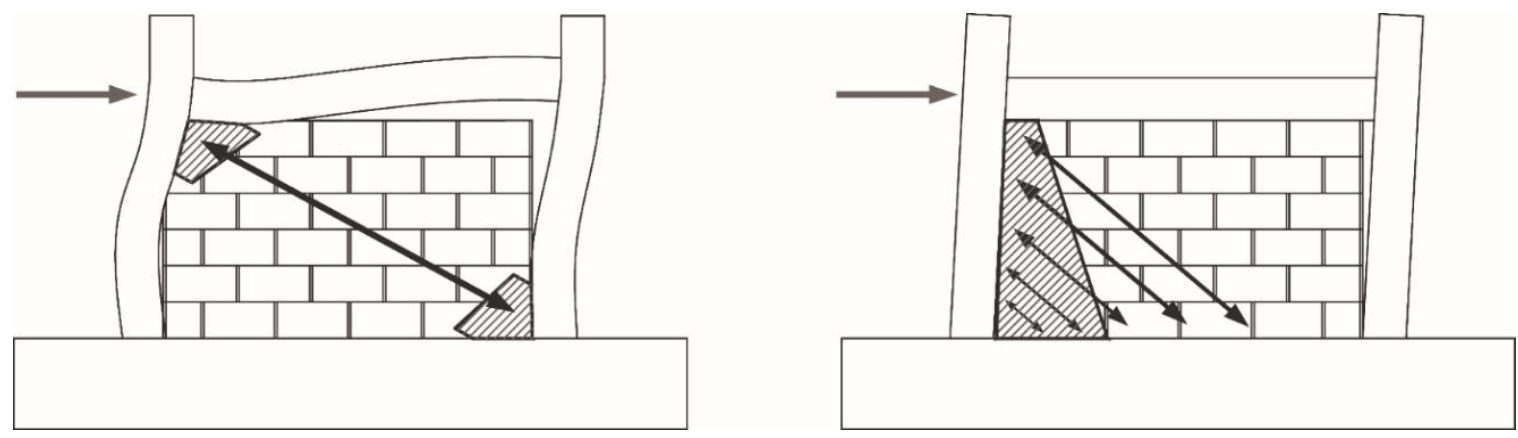
Figure 8 Failure mechanisms of infill walls: (a) corner crushing/diagonal cracking, and (b) widespread cracking

\section{Seismic evaluation of infilled SCB-MFs}

The lateral contribution of infill walls to SCB-MFs was analysed in this section through experimental and numerical approaches, which had a twofold objective: (a) to explore the failure mode of infill walls in self-centring frames, and (b) to validate the calibrated hysteretic values of the infillo1 material. The design details about the specimen dimensions and sections can be found in Huang et al. (2019). Because this reference may not be available, some necessary information about the specimen is provided here. A self-centring-beam is an innovative shopfabricated structural member that incorporates a gap-opening mechanism in its body. Figure 9 shows the configuration of a previously tested SCB-MF specimen. The self-centring-beam is comprised of upper and lower beams. Four bundles of steel strands are systematically post-tensioned on frictional restrainers to keep the two parts assembled. The same wide flange section is employed for the two beam parts, which can serve as a push rod to push the restrainers and achieve the gap-opening mechanism during lateral loading. The beam ends are pinned to columns to achieve a free rotation behaviour when the two beam parts move away from each other. The energy dissipation of the beam occurs through friction movement between the beam ends and friction plates, while post-tensioning strands re-centre the system. Therefore, no damage is expected to occur to the beam within the design drift.

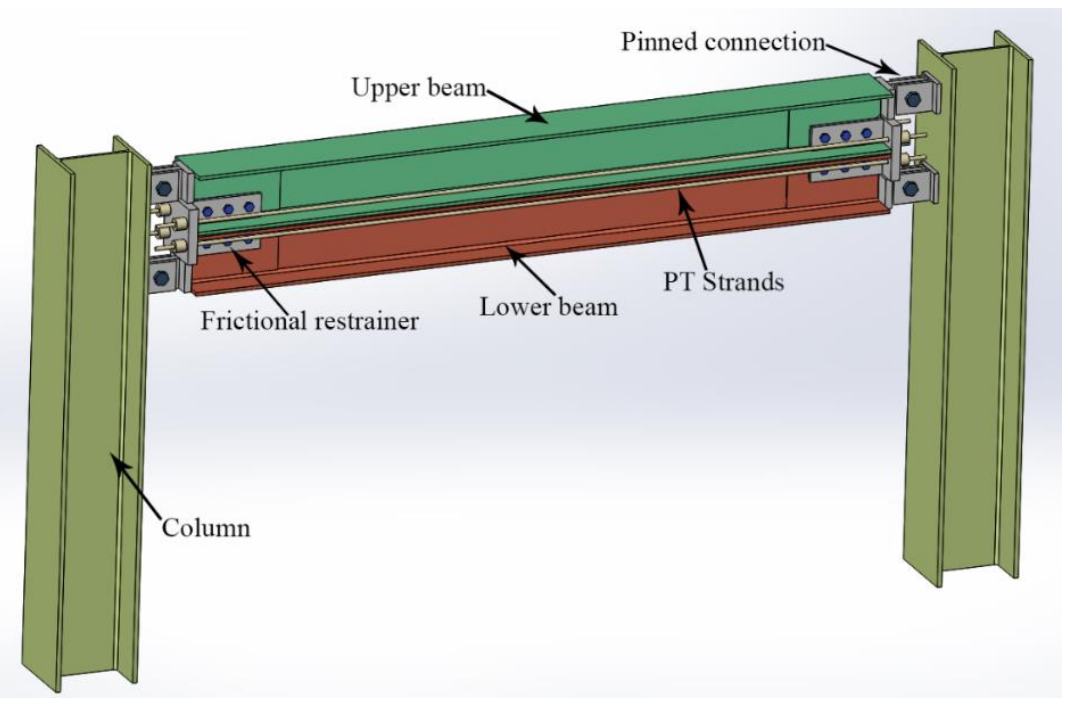

Figure 9 Tested configuration of SCB-MF

\subsection{Static cyclic tests}

The experimental program consisted of diagonal masonry tests and half-scale infilled SCB-MF tests, as shown in Figure 10. The frame that had been previously tested under cyclic loading (Huang et al. 2019) was loaded by adding AAC masonry. The adopted masonry type was the same as that for specimen IW1 in Yang's experiment, which represented a typical construction typology used in China. The diagonal compression test of the masonry prisms was conducted to obtain the Young's modulus $\left(E_{\mathrm{d}}\right)$ and cracking strength $\left(f_{\mathrm{d}}\right)$ of the infill walls in the diagonal direction. The displacement protocol for the infilled specimen was carried out twice consecutively. The drift amplitudes gradually increased to seven different levels, which were $\pm 0.375 \%, \pm 0.5 \%, \pm 0.75 \%, \pm 1.0 \%, \pm 1.5 \%, \pm 2.0 \%$, and $\pm 3.0 \%$. The vertical distance from the loading centre to pin centre of the column bottom was $2000 \mathrm{~mm}$; and the horizontal 
distance between the centrelines of the left and right columns was $3810 \mathrm{~mm}$. The beams and columns were HW $250 \times 250 \times 9 \times 14$ and HW350 $\times 350 \times 12 \times 19$ sections, respectively.

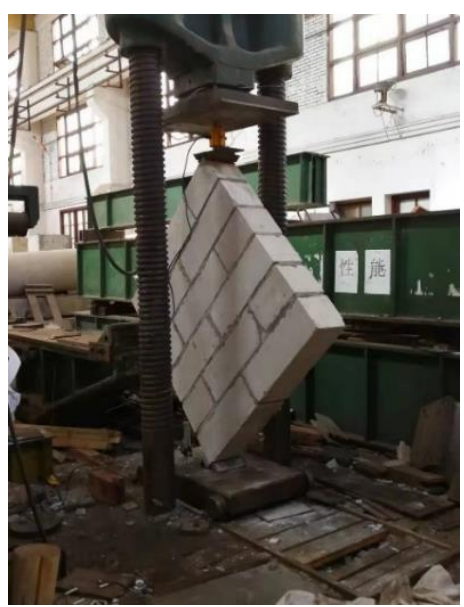

(a) Diagonal test of masonry prisms

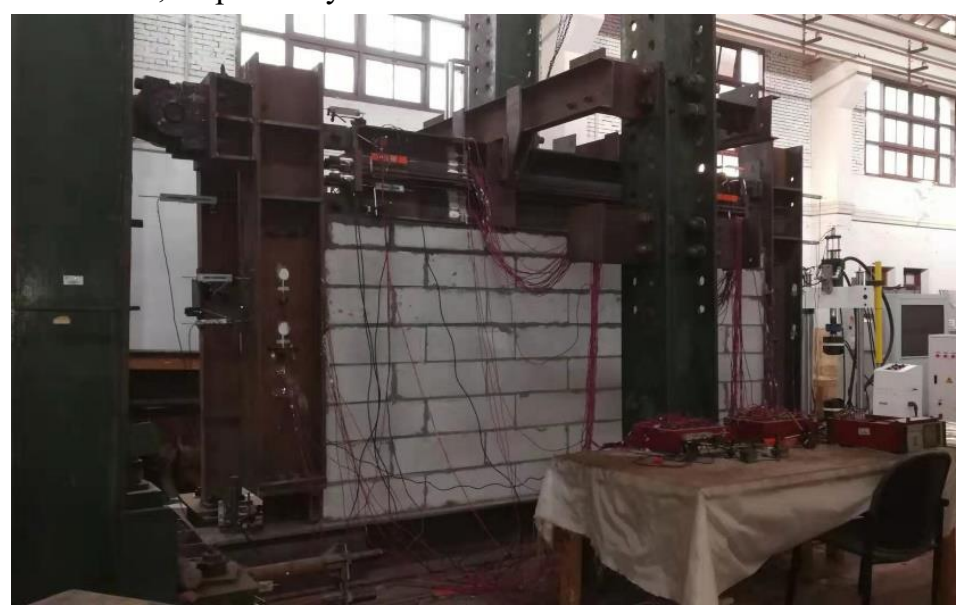

(b) Static cyclic test of infilled SCB-MF

Figure 10 Photograph of specimen and loading device

The energy dissipation of self-centering beam depends on the frictional mechanism. To understand the effect of the infill wall on the energy dissipation of the SCB-MF, all the bolts were untorqued in the restrainers of the specimen and therefore the hysteresis loop was mainly contributed by the infills in the experiment. This provided a good reference for experimental validation of the proposed material. Specimens PTB1-PTB4 in Huang et al. (2019) were used with only the post-tensioning strands active. The experiment for the infilled specimen was conducted after performing cyclic tests on specimen PTB4. Figure 11 shows the final cracking of the infill wall after the entire loading. The frame-infill interaction did not induce any obvious concrete spalling in the wall. The damage to the wall was mainly concentrated at the two sides near the columns, with almost no damage in the middle part of the wall. The crack propagation of this region was a result of the confinement of the bounding frame along the column height. The relative rotation in the joints reduced the bearing action against the wall, and therefore no corner crushing was observed in the experiment. This phenomenon was consistent with the widespread cracking failure mode described previously.
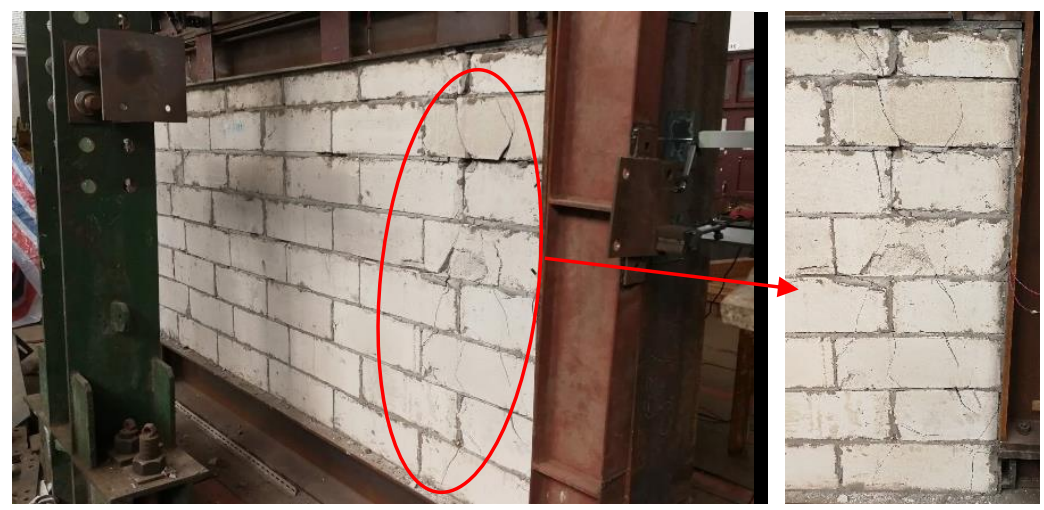

Figure 11 Crack propagation of infill wall after cyclic loading

Figure 12 compares the hysteretic responses of the SCB-MFs with infill walls. The hysteretic result of specimen PTB4 is provided here to show the lateral contribution of the surrounding frame. The gap-opening point is highlighted 
in the figure. It can be seen that the existence of the infill wall significantly improved the energy dissipation of the bare specimen. The hysteretic response of the infilled specimen demonstrated a continuous reloading path and envelope curve similar to those in pinned frames. The maximum lateral load of the infilled specimen increased by $109.3 \%$ in the first run and $84.6 \%$ in the second run compared to the bare specimen, suggesting that an infill wall could continue to contribute to the lateral responses of the frame with the same displacement amplitude. The initial stiffness of the first loading cycle increased by $286.8 \%$ after the infill wall was constructed in the frame. The initial stiffness of the following cycle rapidly decreased and finally reached the value of the bare specimen. However, the specimen stiffness after the gap-opening was still increased by the infill wall after a large number of lateral loading cycles. The residual drift in the specimen was not affected by the infill cracking because of the negligible tensile interaction between the wall and the frame.
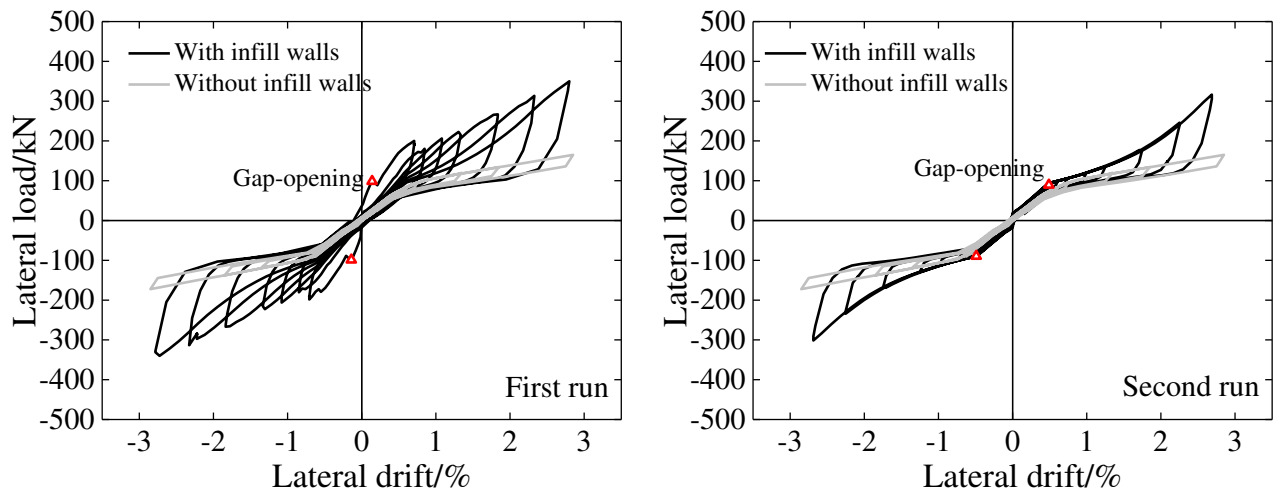

Figure 12 Hysteretic responses of SCB-MFs with and without infill walls

A numerical model was developed for the infilled SCB-MF using the OpenSees software. The columns were represented as nonlinearBeamColumn elements using the Steel02 material. The self-centring-beam was idealised with an elastic element and two flexural springs at the ends. The rotational spring element was assigned the SelfCentering material to represent the moment-rotation characteristics resulting from the gap-opening mechanism. The infill wall was equivalent to a single diagonal strut assigned the infill01 material and Hysteretic+ENT material.

The simulated response of each model is compared with the experimental results in Figure 13. The responses during the largest cycle (peak cycle) of loading are highlighted in the figure. The hysteretic response of infill walls in SCB-MFs demonstrated a continuous reloading path and envelope curve similar to those in pinned frames. Therefore, the hysteretic parameters of the infill01 material were input with reference to specimen IW1 (by comparing Table 3 and Table 4). Referring to Figure 13(a-b), the following main observations can be made: (1) the infillo1 material successfully captured the continuous change in the reloading stiffness due to the continuum nature of infill walls, and (2) the infill01 material was able to simulate the reloading degradation at every other cycle of the constant displacement amplitude. However, the combination of the Hysteretic material and ENT material did not reproduce the infill resistance prior to reaching its previous peak deformation and maintained a constant peak strength under the same displacement amplitude.

Table 4. Calibrated Infillo1 material parameters for tested specimen

\begin{tabular}{ccccccccc}
\hline Specimen & $E_{\mathrm{d}} / \mathrm{GPa}$ & $f_{\mathrm{d}} / \mathrm{MPa}$ & $n$ & $g k_{1}$ & $g k_{2}$ & $b$ & $Q$ & $R$ \\
\hline PTB4 & 235 & 0.12 & - & 0.25 & 1.2 & 0.5 & 0.2 & 10 \\
\hline
\end{tabular}



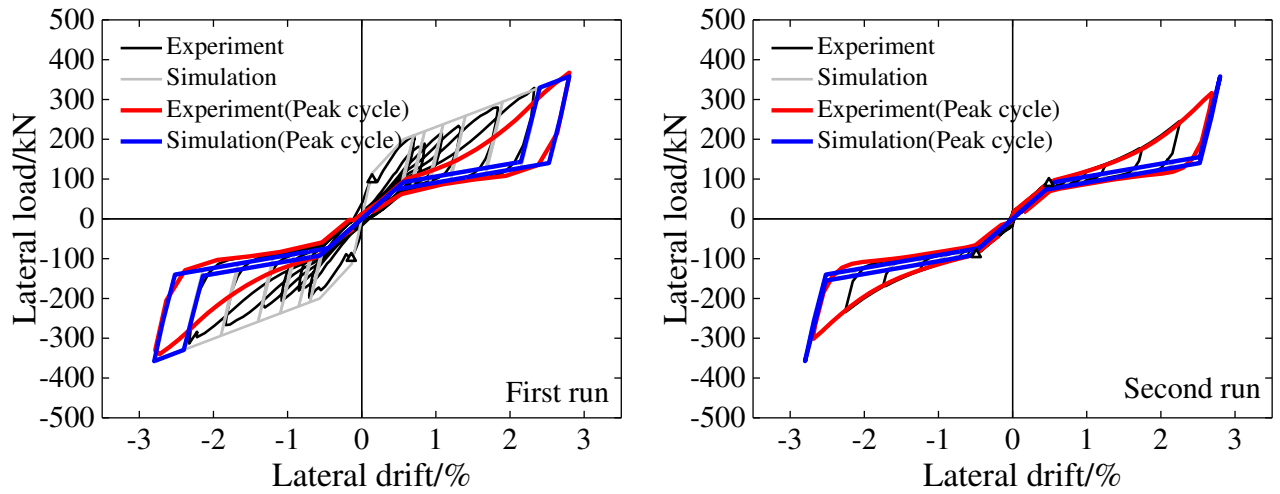

(a) Hysteretic+ENT
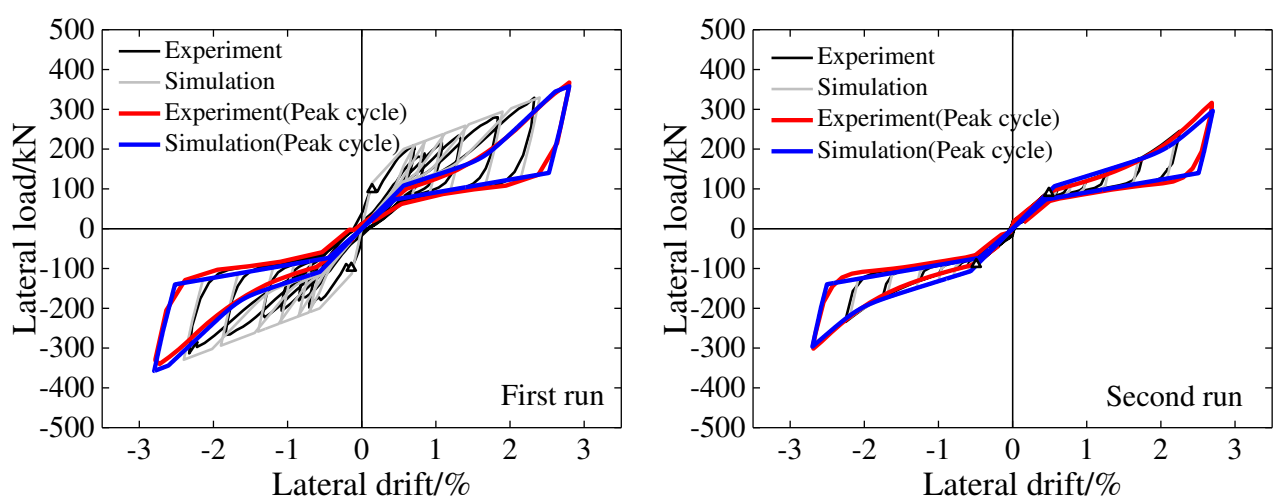

(b) Infillo1

Figure 13 Comparison of observed and experimental responses of infilled SCB-MF

\subsection{Nonlinear dynamic analysis}

A range of infilled SCB-MFs with different building heights were analysed under dynamic loading. Figure 14(a) shows the plan view and seismic information of the building studied. Four building heights were considered: 3, 6, 9, and 12 storeys, with a first storey height of $4.5 \mathrm{~m}$ and an upper storey height of $3.9 \mathrm{~m}$. The structural system was composed of three-bay perimeter SCB-MFs to resist lateral loads and interior gravity frames. One quarter of the building was analysed using a two-dimensional model considering the symmetry of the building plan. The P-delta effects associated with the gravity frames were taken into account by linking a leaning gravity column, which was modelled as beam-column elements joined by zero length rotational spring elements with negligible stiffness, as shown in Figure 14(b). The floor mass was concentrated at the nodes of the lean-on column at the floor level. The design demands for the 3-storey and 6-storey buildings were established using an equivalent lateral force procedure, and those for the 9-storey and 12-storey buildings were established using a modal response spectrum analysis. The member sections were assumed to be made of ASTM A992 steel and are shown in Figure 15. The beams and columns were initially selected assuming that the frame was a "special moment frame". The beams were re-designed as SCBs using the equal initial stiffness and peak moment capacity at the beam ends. The initial stiffness and maximum self-centring moment of the rotational spring were therefore determined. The gap-opening moment and second stiffness of the rotational spring could also be calculated based on the maximum self-centring moment. More details about the equivalent design procedure can be found in Huang et al. (2020) 
The analyses were performed on both bare and infilled SCB-MFs to show how the existence of infill walls could influence the seismic performance. Four types of masonry were examined using the Infillo1 material and represented by four infilled cases. Time history analyses of Case 1 and Case 4 were conducted based on the material parameters of specimens IW1 and IW2 listed in Table 3, respectively. To understand the effect of diagonal infill strength $f_{\mathrm{d}}$ on the lateral contribution of the infill walls, the $f_{\mathrm{d}}$ value of Case 1 and Case 4 was adjusted to $0.4 \mathrm{MPa}$ in Case2 and Case3, respectively. An ensemble of twenty ground motions (La01-La20) developed by Somerville et al. (1997) was used for ground motions excitations. This ensemble is representative of earthquakes in Los Angeles with an exceedance probability of $10 \%$ in 50 years, which is defined as the DBE in ASCE 7-16 (2016). The DBE ground motions were scaled by a factor of 1.5 to investigate the seismic responses of the studied frames under MCE level ground motions.
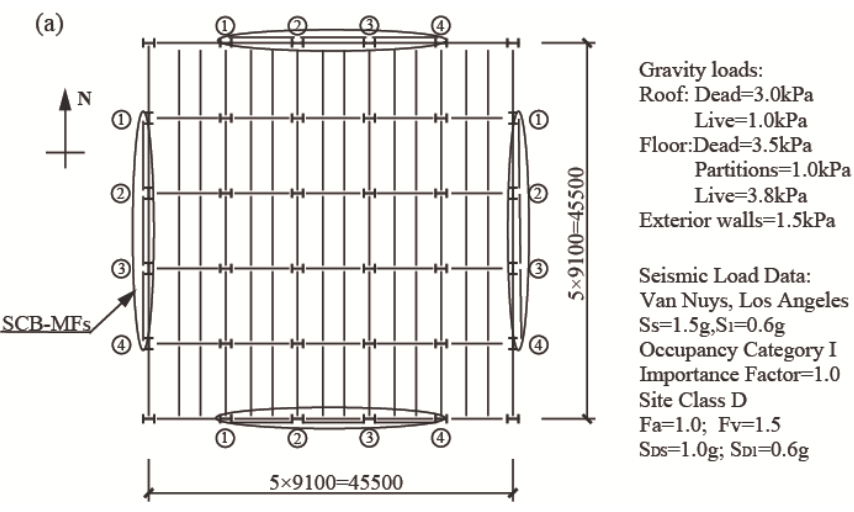

(b)

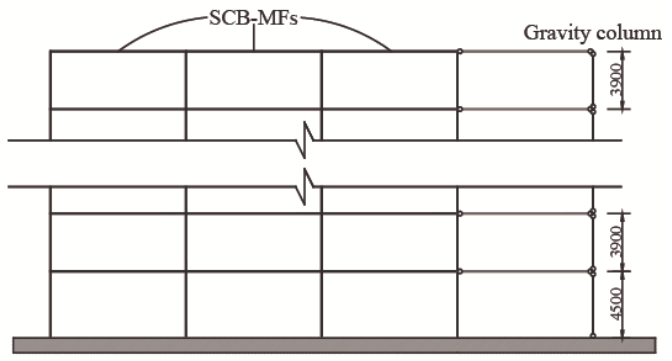

Figure 14 (a) Plan of prototype building, and (b) elevation of prototype frame

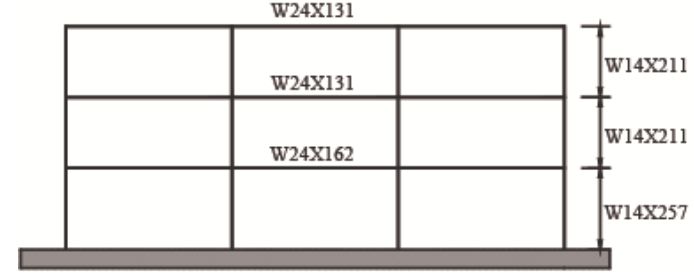

(a) 3-storey prototype

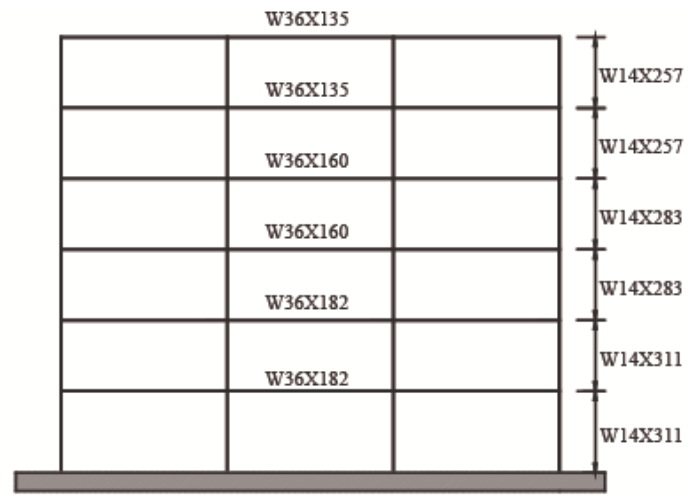

(b) 6-storey prototype 


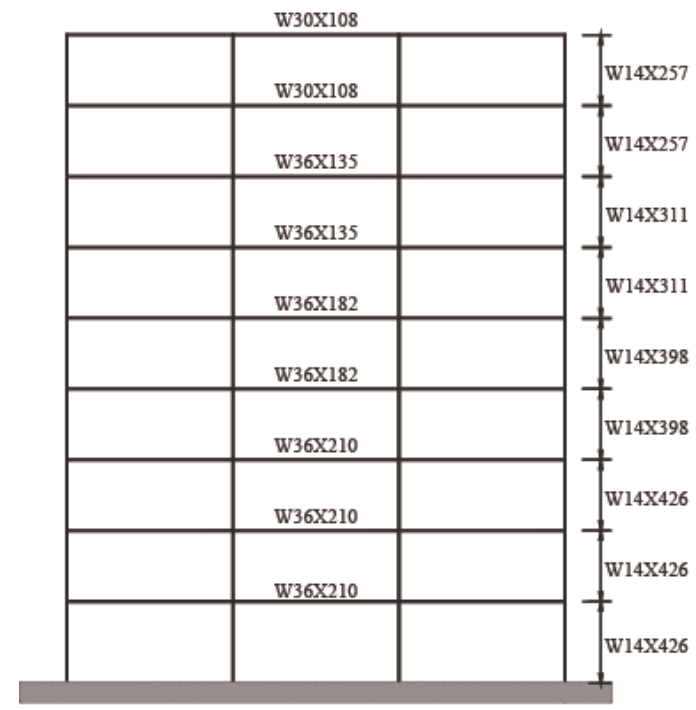

(c) 9-storey prototype

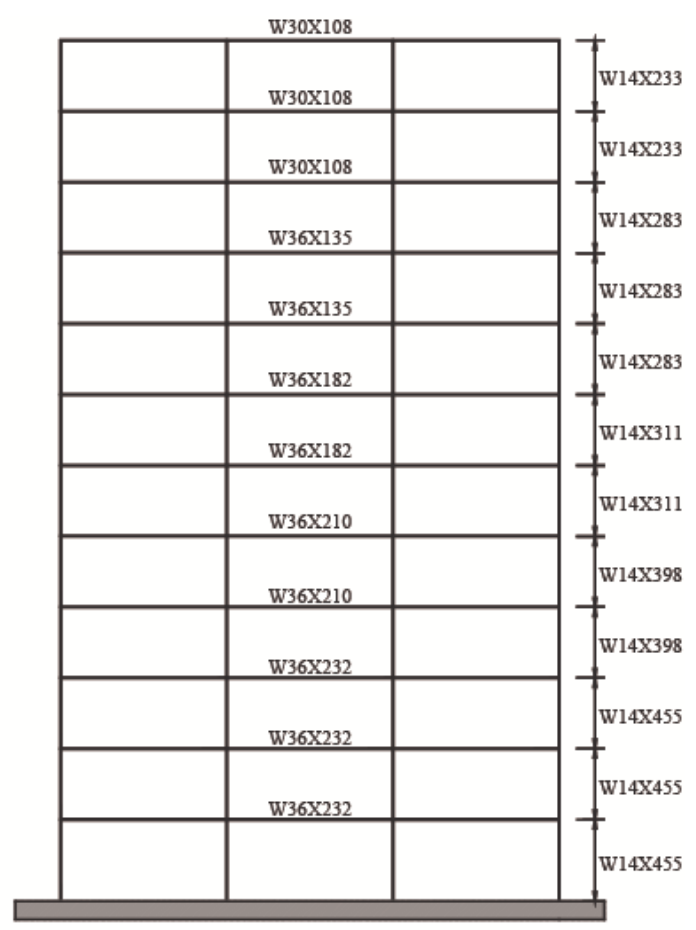

(d) 12-storey prototype

Figure 15 Beam and column sections of SCB-MFs with different numbers of storeys

Natural vibration analyses were performed for the bare and infilled cases before performing nonlinear timehistory analyses. Table 5 summarises the fundamental periods for the SCB-MFs with the different numbers of storeys, with and without infill walls. The fundamental periods for the 3-, 6-, 9-, and 12-storey bare SCB-MFs were 1.02s, $1.59 \mathrm{~s}, 2.13 \mathrm{~s}$, and $2.88 \mathrm{~s}$, respectively. The infill walls were effective in increasing the initial stiffness in the infilled cases and therefore significantly reduced the fundamental periods of the frames.

Table 5. Comparison of initial periods of SCB-MFs with different numbers of storeys with and without infill

\begin{tabular}{cccccc}
\multicolumn{7}{c}{ walls } \\
\hline \multirow{2}{*}{ Period } & \multirow{2}{*}{ Bare frame } & Case1 & Case 2 & Case 3 & Case 4 \\
\hline 3-storey & $1.02 \mathrm{~s}$ & $0.57 \mathrm{~s}$ & $0.57 \mathrm{~s}$ & $0.24 \mathrm{~s}$ & $0.24 \mathrm{~s}$ \\
6-storey & $1.59 \mathrm{~s}$ & $1.01 \mathrm{~s}$ & $1.01 \mathrm{~s}$ & $0.46 \mathrm{~s}$ & $0.46 \mathrm{~s}$ \\
9-storey & $2.13 \mathrm{~s}$ & $1.46 \mathrm{~s}$ & $1.46 \mathrm{~s}$ & $0.71 \mathrm{~s}$ & $0.71 \mathrm{~s}$ \\
12-storey & $2.88 \mathrm{~s}$ & $1.97 \mathrm{~s}$ & $1.97 \mathrm{~s}$ & $1.01 \mathrm{~s}$ & $1.01 \mathrm{~s}$ \\
\hline
\end{tabular}

The seismic responses of the SCB-MFs for the different infill cases were characterised using the peak interstorey drift ratio (IDR) and residual drift ratio (RDR). Figure 16 shows the mean values of these system indices in relation to the building height under the selected earthquake ensemble. The top storey drift showed the largest reductions for the SCB-MFs with the different numbers of storeys. Take Case 1 as an example, the peak IDR values for the 3-, 6-, 9-, and 12-storey SCB-MFs were mainly concentrated at the low to middle storeys, which were $16.5 \%$, $16.3 \%, 9.3 \%$, and $4.5 \%$ lower than those for the corresponding bare frames, respectively. However, there were $30.9 \%$, $22.6 \%, 24.6 \%$, and $20.1 \%$ reductions in the top storey drift, respectively. This was because the lateral shear distribution along the building height could easily induce sudden losses in the infill strength and stiffness in the lower storeys of 
uniformly infilled cases. The peak IDR values for the 3-, 6-, 9-, and 12-storey SCB-MFs varied by 7.9\%, 1.6\%, 7.6\%, and $0.3 \%$, respectively, in a comparison of Case 1 and Case 3 , and by $9.6 \%, 7.7 \%, 7.2 \%$, and $1.5 \%$, respectively, in a comparison of Case 2 and Case 4 . These numbers indicated that despite the variation of the infill diagonal strength, the peak IDR profiles did not change much. Moreover, all the infill cases showed decreases in the RDR distribution as a result of the decreasing peak IDR.
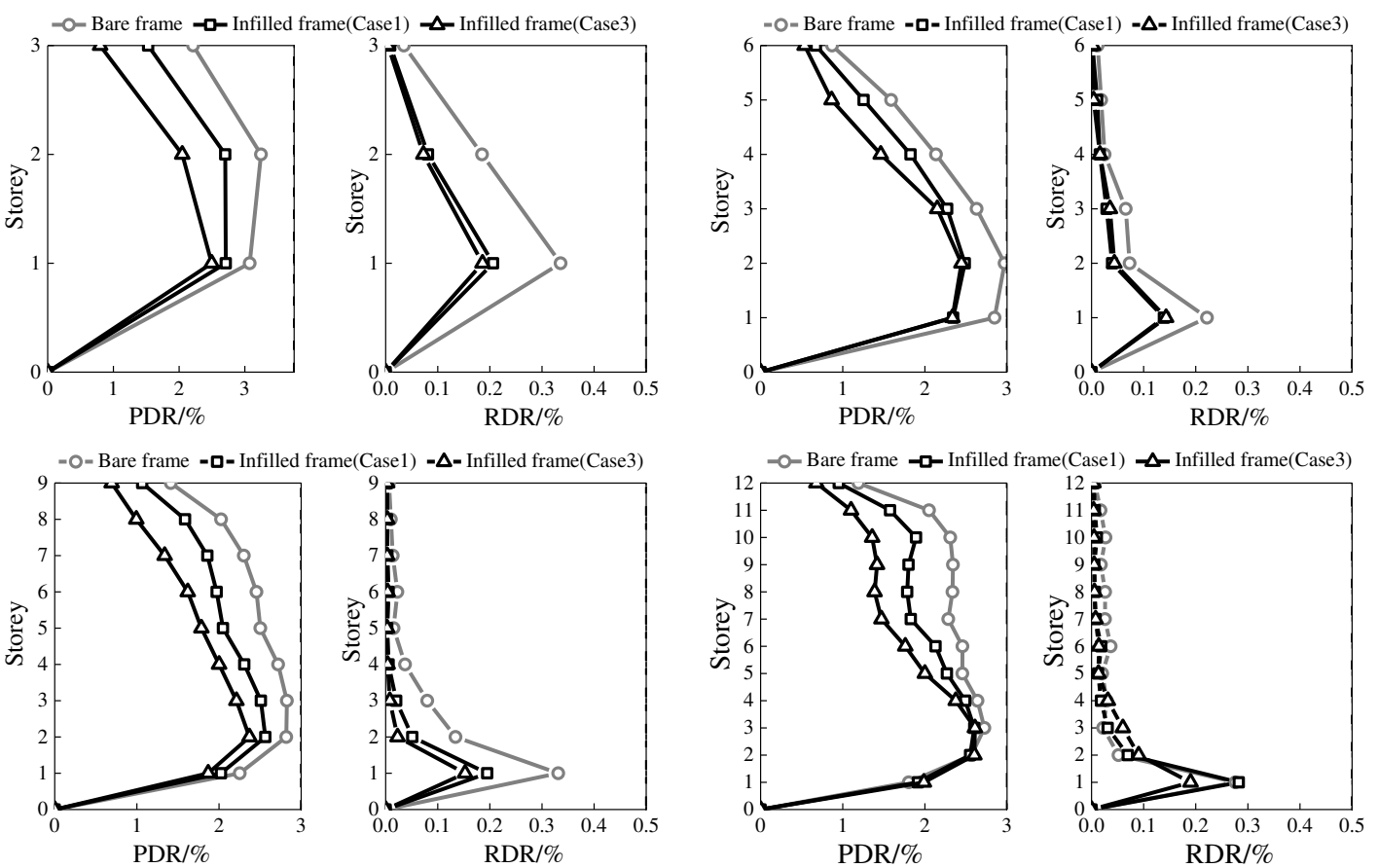

(a) AAC masonry
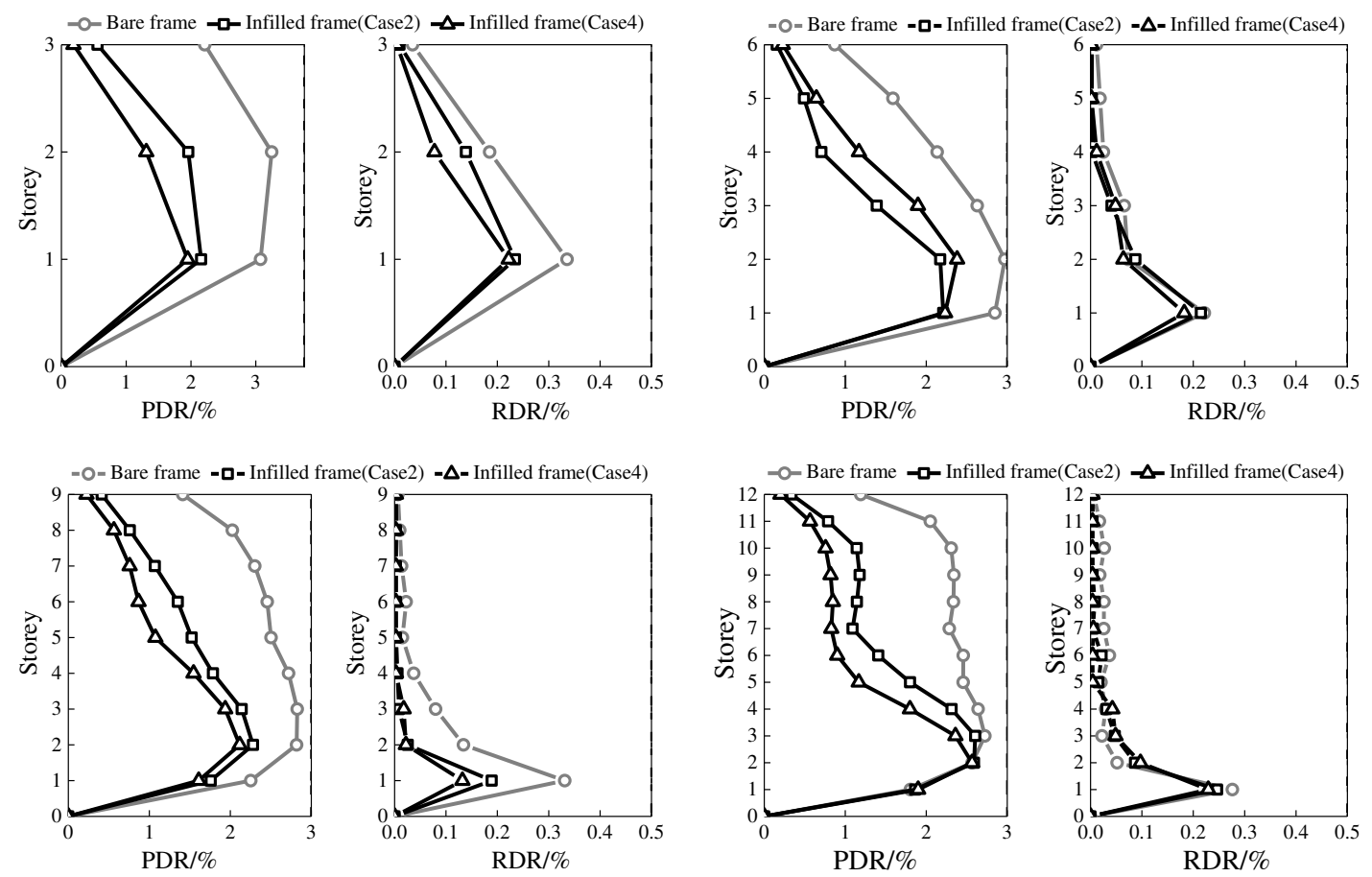

(b) PC masonry 


\section{Figure 16 Statistics for seismic responses in relation to height for SCB-MFs with and without infill walls under MCEs}

An example of the results from one response history analysis under the La03 ground motion is presented to demonstrate the dynamic characteristics of the diagonal strut, which are representative of many of the analyses conducted. The scaled peak ground acceleration (PGA) of the La03 ground motion was 0.64 g, as shown in Figure 17. Figure 18 gives the axial force-axial deformation relationships of the infill walls located at the exterior bay of some storeys in Case4 under the La03 motion. The hysteretic responses demonstrate the proposed material is capable of capturing the dynamic behaviours of infill walls under the asymmetric loading protocol. The infill walls at the bottom storeys suffer a rapid concentration of damage under larger deformation histories, whereas those at the top storeys remained almost elastic. This phenomenon was most significant with a larger building height. These distributions provided an explanation of the peak drift demands of the infilled cases. The peak IDR values for the lower storeys of the infilled cases increased to close to those in the bare case because of the rapid accumulation of infill damage. The undamaged infill walls in the upper storeys provided additional stiffness and strength to the bounding frame, which caused obvious reductions in the peak IDR values of the infilled cases.

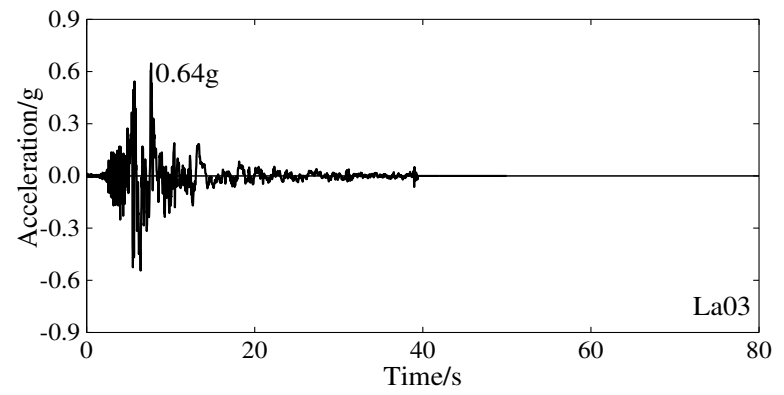

Figure 17 Acceleration time histories of scaled La03 record at MCE level
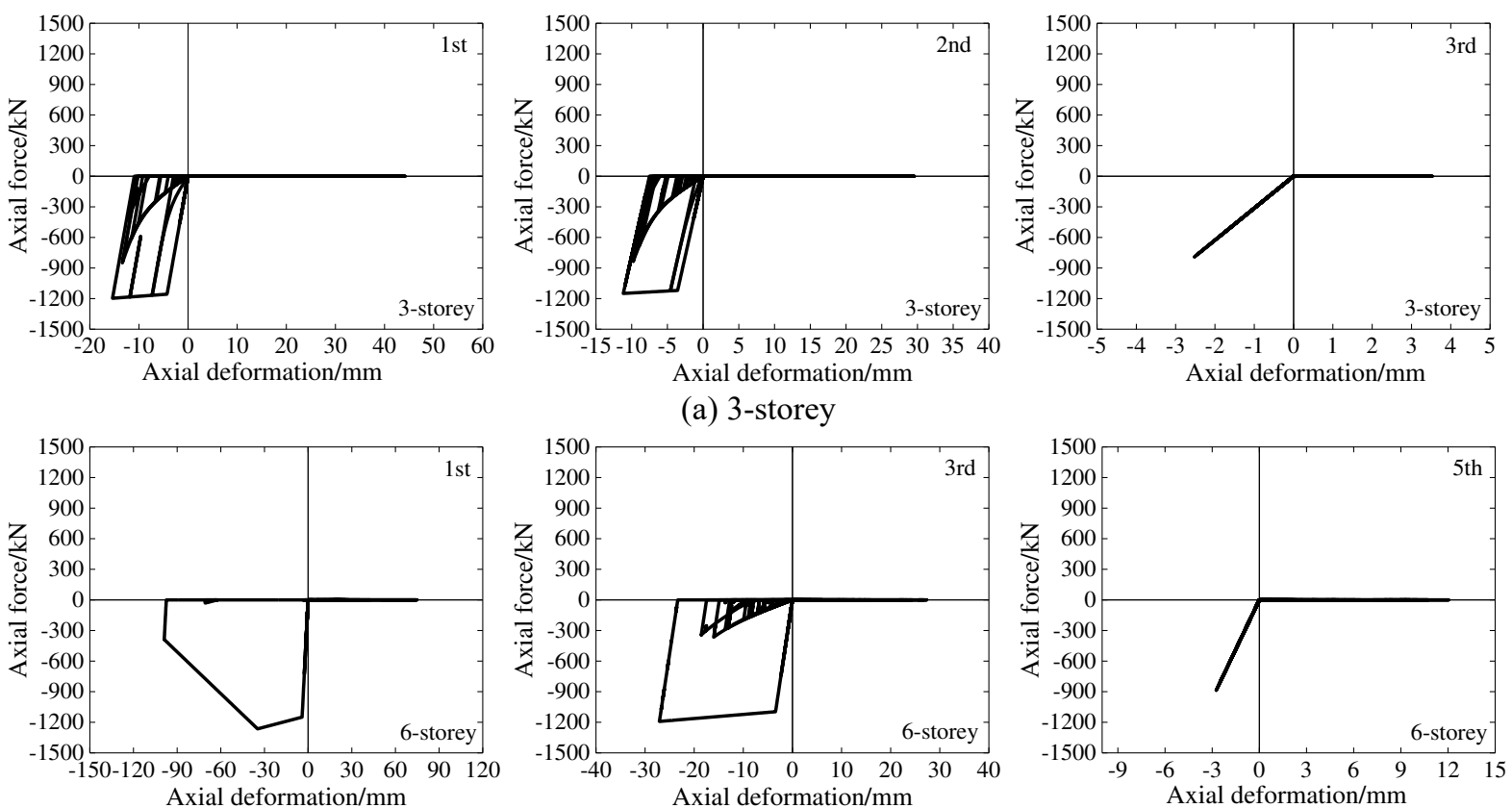

(b) 6-storey 

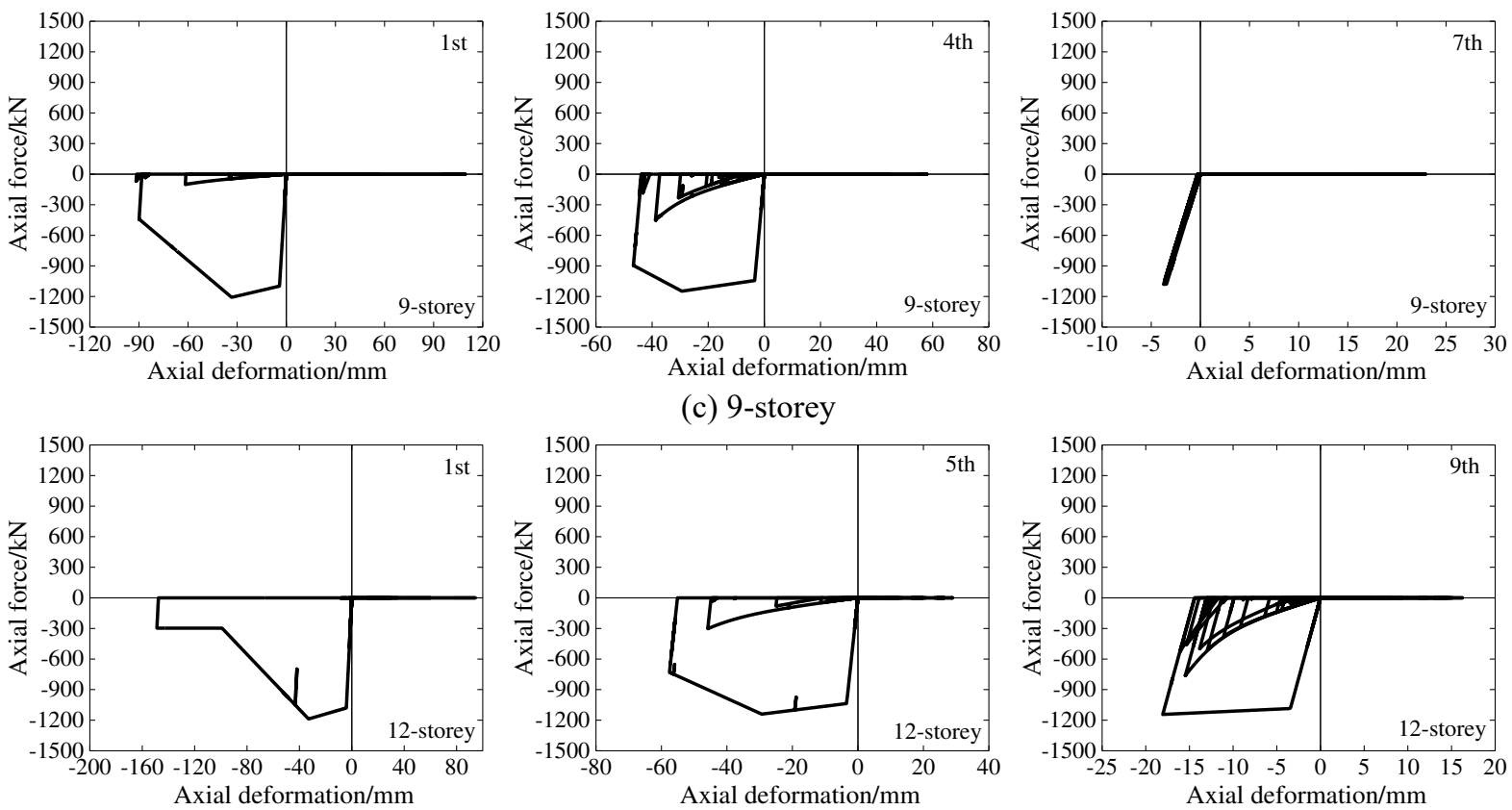

(d) 12-storey

Figure 18 Hysteretic responses of equivalent struts for masonry infill walls at various storeys under La03 motion

\section{Conclusion}

The following conclusions can be drawn based on the simulated and experimental results:

(1) An efficient phenomenological hysteretic model simulating the infill walls was presented in the paper which had predicted different experimental behaviour with accuracy. The backbone parameters were determined using the existing envelope models. The hysteretic parameters were calibrated using the results of different groups of previous experiments. Parameters $g k_{2}$, beta, and $Q$ were found to be approximately constant. Parameters $g k_{1}$ and $R$ were calibrated using different values because of the great variability in the masonry materials and boundary conditions, but the calibrated values for the two parameters could provide references for future simulations using different types of infilled frames.

(2) Experimental cyclic tests on the SCB-MFs with infill walls were first performed. The confinement from bounding columns on the infill wall produced no strength degradation in the envelope curve because of the free rotation of the joints. The frame-infill interaction was observed to be similar to that in pinned frames. Based on the calibrated hysteretic parameters for specimen IW1, the proposed material could accurately reproduce the hysteretic response of the infilled SCB-MFs.

(3) The seismic responses of 3-, 6-, 9-, and 12-storey SCB-MFs with and without infill walls were analysed. Nonlinear dynamic analyses validated the feasibility of using the proposed model to simulate the dynamic behaviours of infill walls. Seismic excitation led to a very uneven distribution of damage in the infill walls of different storeys. The variation in the infill diagonal strength had a slight effect on the peak interstorey drift ratios (IDR) of some stories. This was associated with the premature damage to the infill walls in these stories.

(4) The proposed material could be further applied into multiple diagonal struts approach to better capture the interaction forces between infill walls and boundary columns. 


\section{Acknowledgments}

The authors gratefully acknowledge the financial support provided by 'National Natural Science Foundation of China' (52008056), 'Postdoctoral Innovative Talents Support Program' (BX20200071), 'China Postdoctoral Science Foundation' (2020M673140), 'Chongqing Postdoctoral Science Foundation' (cstc2020jcyj-bshX0076), and '2020 annual Open Fund of Failure Mechanics \& Engineering Disaster Prevention and Mitigation, Key Laboratory of Sichuan Province, Sichuan University' (2020JDS0022).

\section{References}

Al-Chaar, G. 2002. Evaluating strength and stiffness of unreinforced masonry infill structures US Army Corps of Engineers, Engineer Research and Development Center.

Alwashali H, Sen D, Jin K, et al. 2019. Experimental investigation of influences of several parameters on seismic capacity of masonry infilled reinforced concrete frame. Engineering Structures 189: 11-24.

ASCE/SEI 7-16. 2016. Minimum Design Loads for Buildings and Other Structures. American Society of Civil Engineers:VA, U.S.A.,

Cavaleri L, Di Trapani F. 2014. Cyclic response of masonry infilled RC frames: experimental results and simplified modeling. Soil Dynamics and Earthquake Engineering 65:224-42.

Celarec D, Ricci P, Dolšek M. 2012. The sensitivity of seismic response parameters to the uncertain modelling variables of masonryinfilled reinforced concrete frames. Engineering Structures 35: 165-177.

Chiozzi A, Miranda E. 2017. Fragility functions for masonry infill walls with in-plane loading. Earthquake Engineering \& Structural Dynamics 46(15): 2831-2850.

Clayton P M, Berman J W, Lowes L N. 2013. Subassembly testing and modeling of self-centering steel plate shear walls. Engineering Structures 56: 1848-1857.

Colangelo F. 2013. Drift-sensitive non-structural damage to masonry-infilled reinforced concrete frames designed to Eurocode 8. Bulletin of Earthquake Engineering 11(6): 2151-2176.

Dimopoulos A I, Karavasilis T L, Vasdravellis G, et al. 2013. Seismic design, modelling and assessment of self-centering steel frames using post-tensioned connections with web hourglass shape pins. Bulletin of Earthquake Engineering, 11(5): 1797-1816.

El-Dakhakhni W W, Elgaaly M, Hamid A A. 2003. Three-strut model for concrete masonry-infilled steel frames. Journal of Structural Engineering 129(2): 177-185.

Fang C, Wang W, He C, et al. 2017. Self-centring behaviour of steel and steel-concrete composite connections equipped with NiTi SMA bolts. Engineering Structures 150: 390-408.

FEMA 356. 2000. Prestandard and commentary for the seismic rehabilitation of buildings. Prepared by the American Society of Civil Engineers, Reston (VI).

Fikri R, Dizhur D, Walsh K, et al. 2019. Seismic performance of reinforced concrete frame with masonry infill buildings in the 2010/2011 Canterbury, New Zealand Earthquakes. Bulletin of Earthquake Engineering 17(2): 737-757.

Garlock M M, Ricles J M, Sause R. 2005. Experimental studies of full-scale posttensioned steel connections. Journal of Structural Engineering 131(3): 438-448.

Huang X, Zhou Z, Xie Q, et al. 2017. Force distribution analysis of self-centering coupled-beams for moment-resisting-frames without floor elongation. Engineering Structures 147: 328-344.

Huang L, Zhou Z, Zhang Z, et al. 2018a. Seismic performance and fragility analyses of self-centering prestressed concrete frames with infill walls. Journal of Earthquake Engineering 1-31.

Huang X, Zhou Z, Hua K, et al. 2018b. Influence of infill configurations on seismic responses of steel self-centering moment 
resisting frames. The Structural Design of Tall and Special Buildings 27(10): e1474.

Huang X, Zhou Z, Eatherton M R, et al. 2019. Experimental Investigation of Self-Centering Beams for Moment-Resisting Frames. Journal of Structural Engineering 146(3): 04019214.

Huang X, Zhou Z, Wang Y. 2020. Seismic design and performance of self-centering-beam moment-frames. Journal of Constructional Steel Research 170: 106089.

Jeon J S, Park J H, DesRoches R. 2015. Seismic fragility of lightly reinforced concrete frames with masonry infills. Earthquake Engineering \& Structural Dynamics 44(11): 1783-1803.

Klingner R E, Bertero V V. 1978. Earthquake resistance of infilled frames. Journal of the Structural Division 104(6):973-89.

Landi L, Tardini A, Diotallevi P P. 2016. A procedure for the displacement-based seismic assessment of infilled RC frames. Journal of Earthquake Engineering 20(7): 1077-1103.

Li B, Wang Z, Mosalam K M, et al. 2008. Wenchuan earthquake field reconnaissance on reinforced concrete framed buildings with and without masonry infill walls. The 14th World Conference on Earthquake Engineering. Beijing, China.

Liberatore L, Noto F, Mollaioli F, et al. 2018. In-plane response of masonry infill walls: Comprehensive experimentally-based equivalent strut model for deterministic and probabilistic analysis. Engineering Structures 167: 533-548.

Liberatore L. 2001. Approcci innovativi in termini di energia e di spostamento per la valutazione della risposta sismica di strutture a più gradi di libertà. PhD Dissertation. University of Rome La Sapienza Rome [in Italian].

Lin C. 2019. Seismic Performance and Interaction Mechanism of Infilled RC Frames Using New Masonry Blocks. PhD dissertation. Quanzhou: Huaqiao University [in Chinese].

Li Y, Liu Y, Chen Z. 2020. Seismic response assessment of a hybrid coupled wall structure with novel self-centering steel truss coupling beams. Bulletin of Earthquake Engineering, 1-24.

Madan A, Reinhorn A M, Mander J B, et al. 1997. Modeling of masonry infill panels for structural analysis. Journal of Structural Engineering 123(10): 1295-1302.

Mander J B, Priestley M J N, Park R. 1988. Theoretical stress-strain model for confined concrete. Journal of Sructural Engineering 114(8): 1804-1826.

Martinelli E, Lima C, De Stefano G. 2015. A simplified procedure for nonlinear static analysis of masonry infilled RC frames. Engineering Structures, 101: 591-608.

Mehrabi AB, Shing B, Schuller MP, Noland JL. 1996. Experimental evaluation of masonry-infilled RC frames. Journal of Structural Engineering 122(3):228-237.

Menegotto M. 1973. Method of analysis for cyclically loaded RC plane frames including changes in geometry and non-elastic behavior of elements under combined normal force and bending. Proc. of IABSE symposium on resistance and ultimate deformability of structures acted on by well defined repeated loads. 15-22.

Moghadam H A, Mohammadi M G, Ghaemian M. 2006. Experimental and analytical investigation into crack strength determination of infilled steel frames. Journal of Constructional Steel Research 62(12): 1341-1352.

Mostafaei H, Kabeyasawa T. 2004. Effect of infill masonry walls on the seismic response of reinforced concrete buildings subjected to the 2003 - bam earthquake strong motion: a case study of Bam Telephone Center. Bulletin of the Earthquake Research Institute, Tokyo 79:133-56.

Mohammad A F, Faggella M, Gigliotti R, et al. 2016. Seismic performance of older R/C frame structures accounting for infillsinduced shear failure of columns. Engineering Structures 122: 1-13.

Noh N M, Liberatore L, Mollaioli F, et al. 2017. Modelling of masonry infilled RC frames subjected to cyclic loads: State of the art review and modelling with OpenSees. Engineering Structures 150: 599-621.

Panagiotakos TB, Fardis MN. 1994. Proposed nonlinear strut models for infill panels. First year progress report for PREC8 network. 
University of Patras.

Polyakov S. 1960. On the interaction between masonry filler walls and enclosing frame when loaded in the plane of the wall. Translations in earthquake engineering 2: 36-42.

Rahnama M, Krawinkler H. 1993. Effects of soft soil and hysteresis model on seismic demands. John A. Blume Earthquake Engineering Center Report No. 108. Department of CEE, Stanford University.

Ricles J M, Sause R, Garlock M M, et al. 2001. Posttensioned seismic-resistant connections for steel frames. Journal of Structural Engineering 127(2): 113-121.

Skoulidou D, Romão X, Franchin P. 2019a. How is collapse risk of RC buildings affected by the angle of seismic incidence?. Earthquake Engineering \& Structural Dynamics 48(14): 1575-1594.

Skoulidou D, Romão X. 2019b. Uncertainty quantification of fragility and risk estimates due to seismic input variability and capacity model uncertainty. Engineering Structures 195: 425-437.

Somerville PG. 1997. Development of ground motion time histories for phase 2 of the FEMA/SAC steel project: SAC Joint Venture.

Tasnimi AA, Mohebkhah A. 2011. Investigation on the behavior of brick-infilled steel frames with openings, experimental and analytical approaches. Engineering Structures 33:968-80.

Wang L, Tang Z Y, Li Y, et al. 2019. Seismic behavior of masonry-infilled precast concrete frames considering effects of opening. Construction and Building Materials 211: 756-770. 
Figures

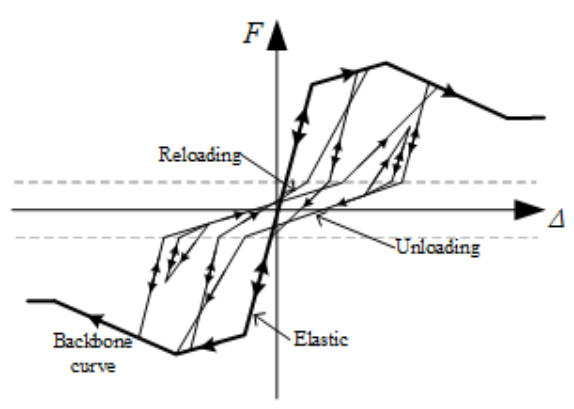

(a) Panagiotakos and Fardis

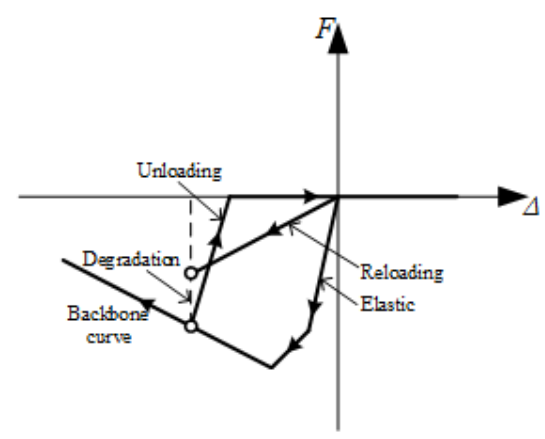

(d) Liberatore

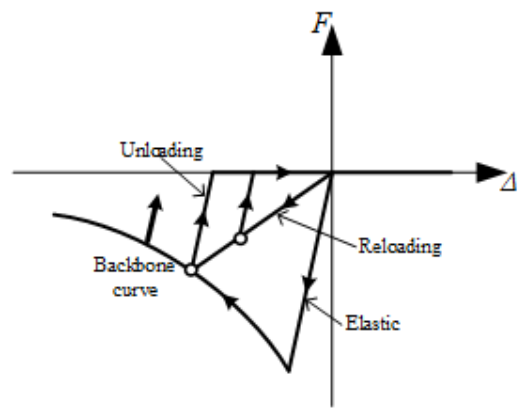

(b) Klingner et al.

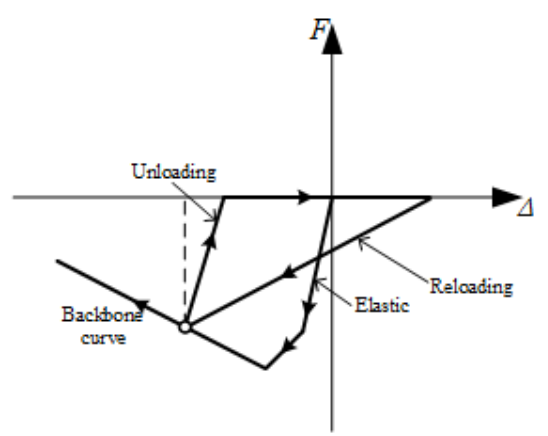

(e) Hyster etic material

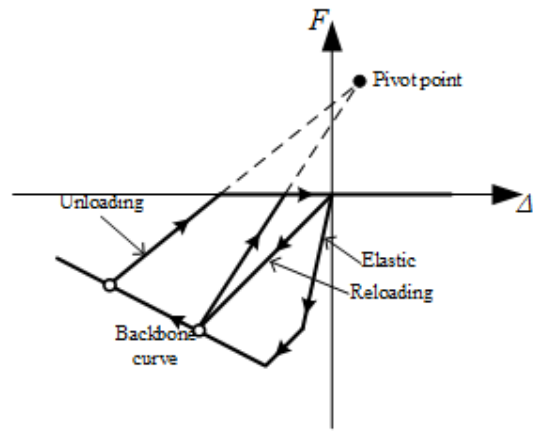

(c) Cavaleri et al.

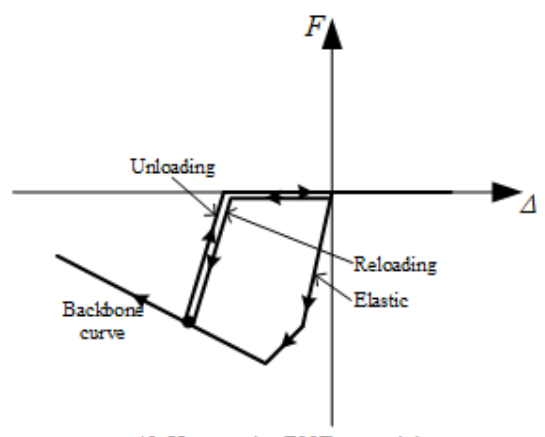

(f) Hysteretic+ENT m aterial

Figure 1

Existing phenomenological models of infill walls

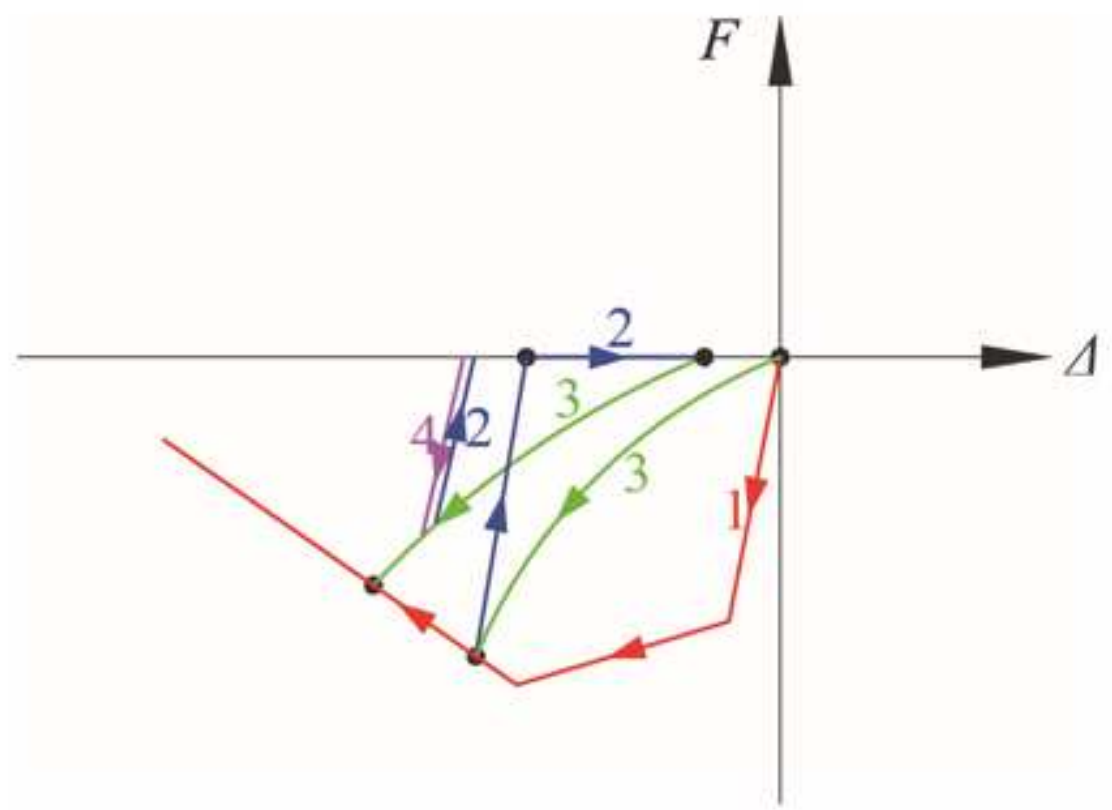

Figure 2

Infill01 material states 


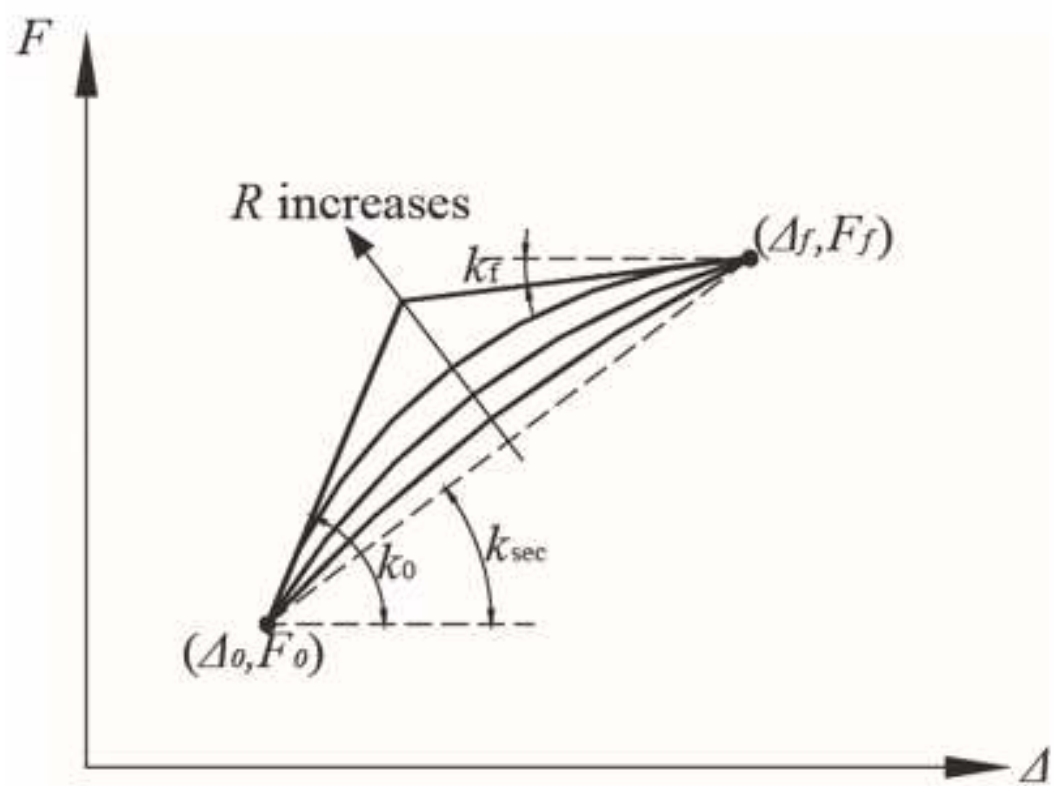

\section{Figure 3}

Illustration of Menegotto-Pinto equation
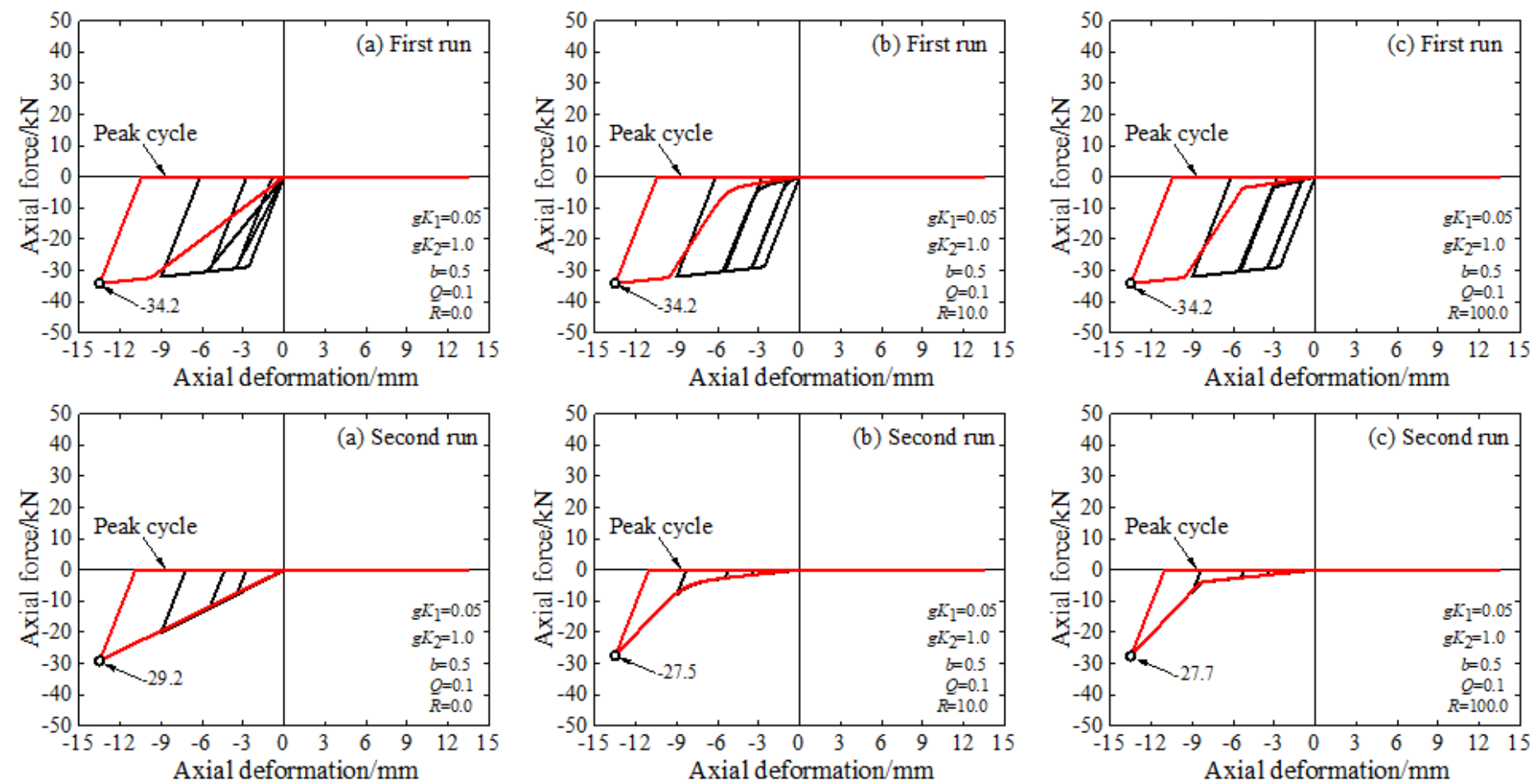

Figure 4

Parametric analysis results for Infill01 material: (a) $R=0.0$, (b) $R=10.0$, and (c) $R=100.0$ 

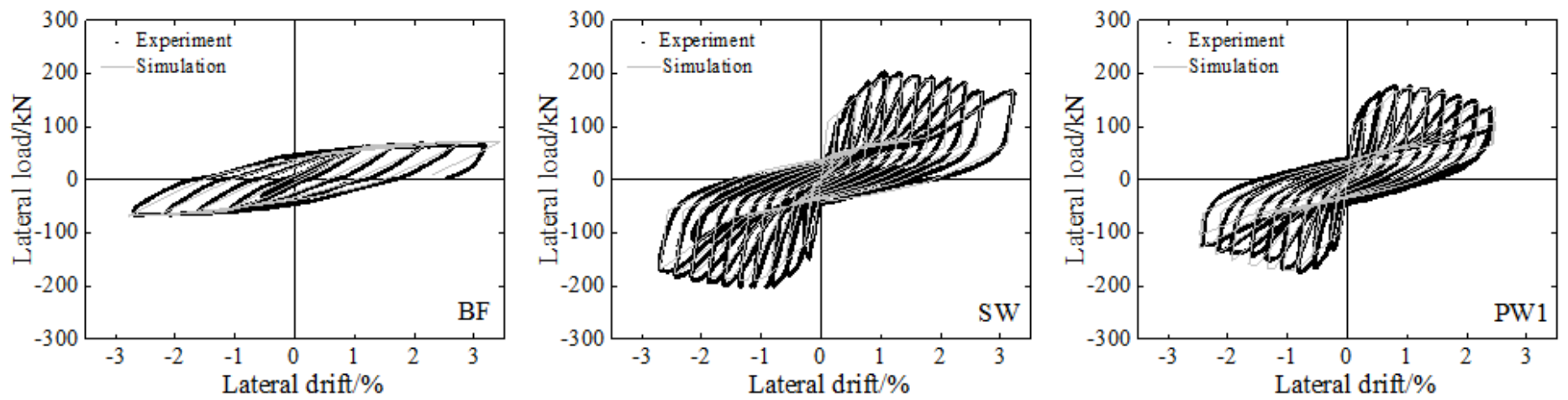

Figure 5

Hysteretic responses of infilled steel moment frame tested by Tasnimi: (a) BF, (b) SW, and (c) PW1
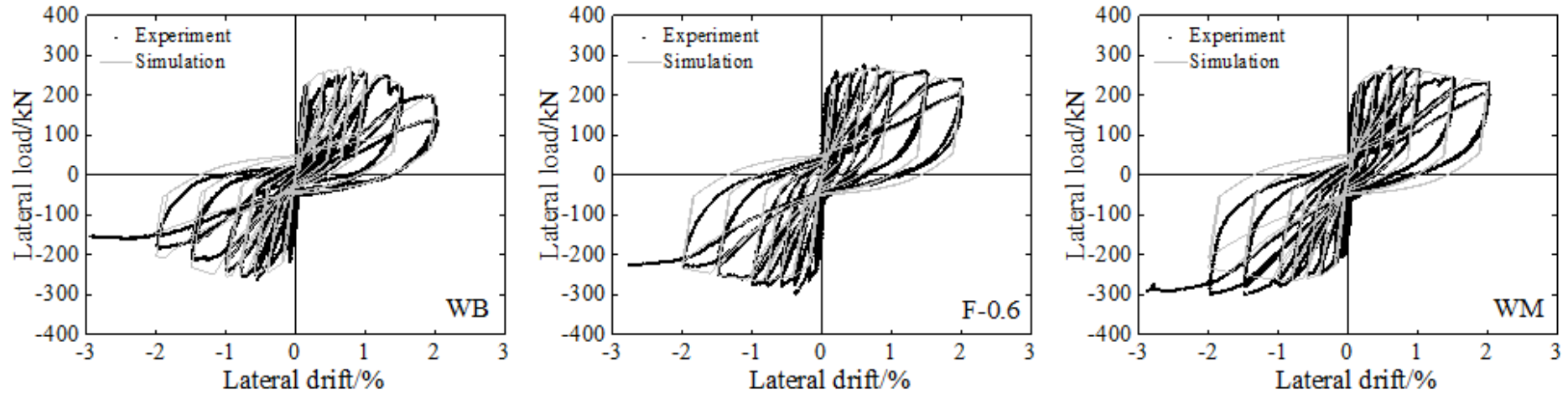

Figure 6

Hysteretic response of infilled concrete moment frame tested by Alwashali: (a) WB, (b) F-0.5, and (c) WM
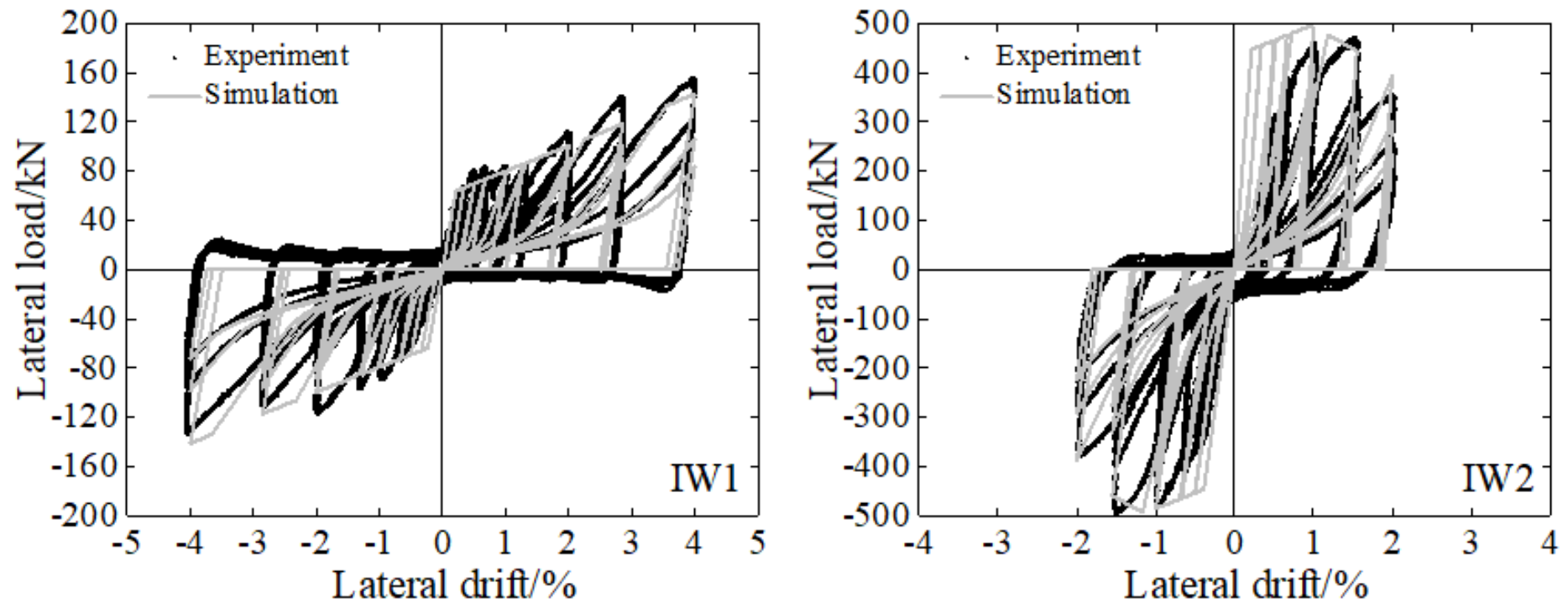

Figure 7

Hysteretic responses of infilled pinned frame tested by Yang: (a) IW1 and (b) IW2 

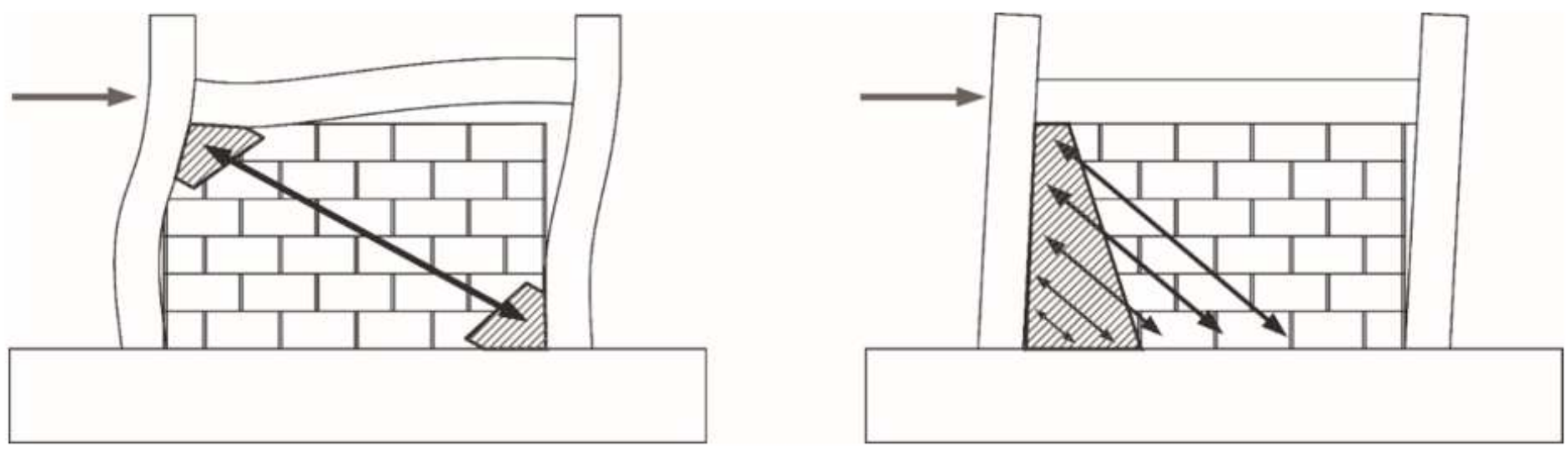

\section{Figure 8}

Failure mechanisms of infill walls: (a) corner crushing/diagonal cracking, and (b) widespread cracking

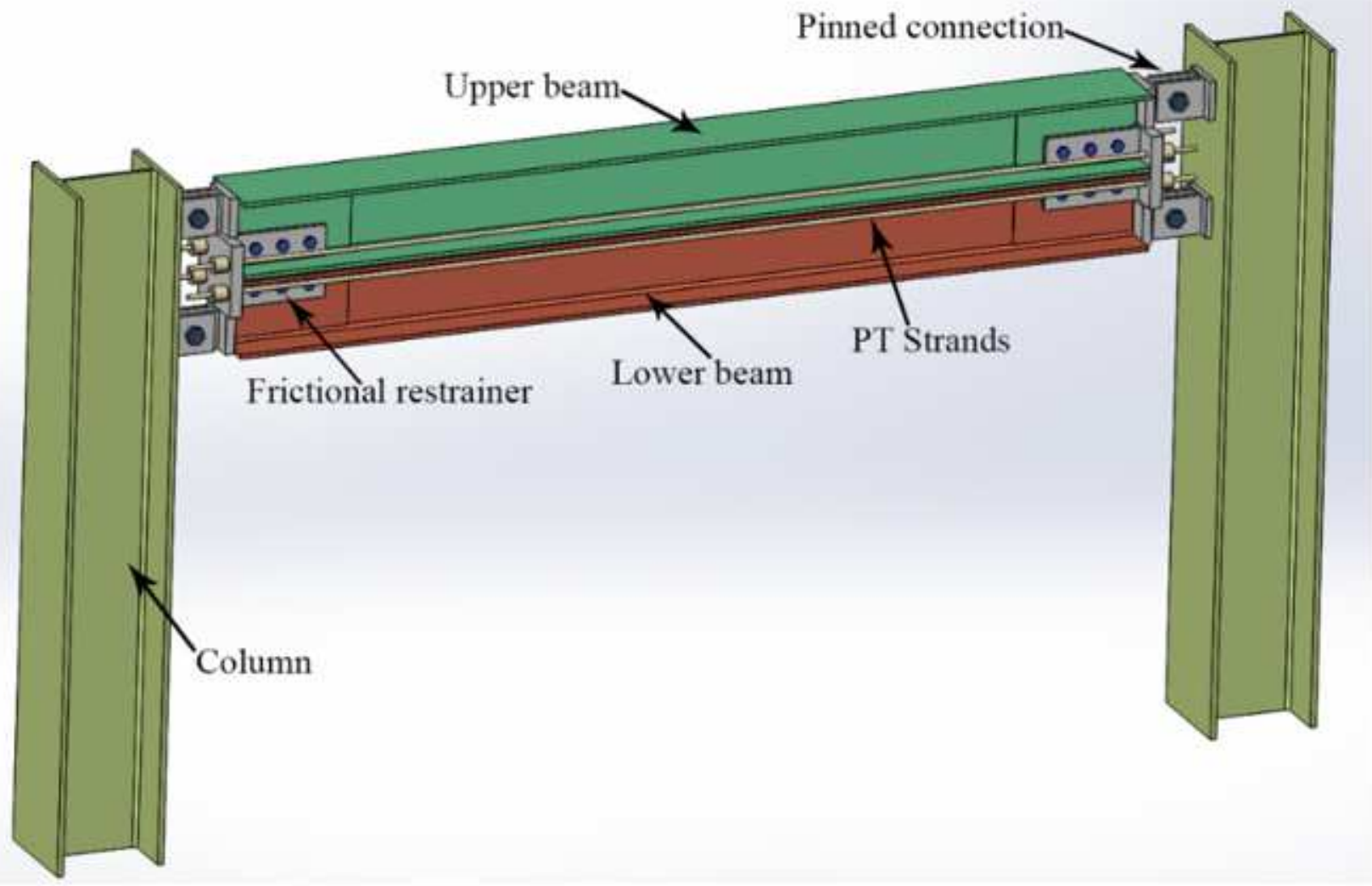

Figure 9

Tested configuration of SCB-MF 


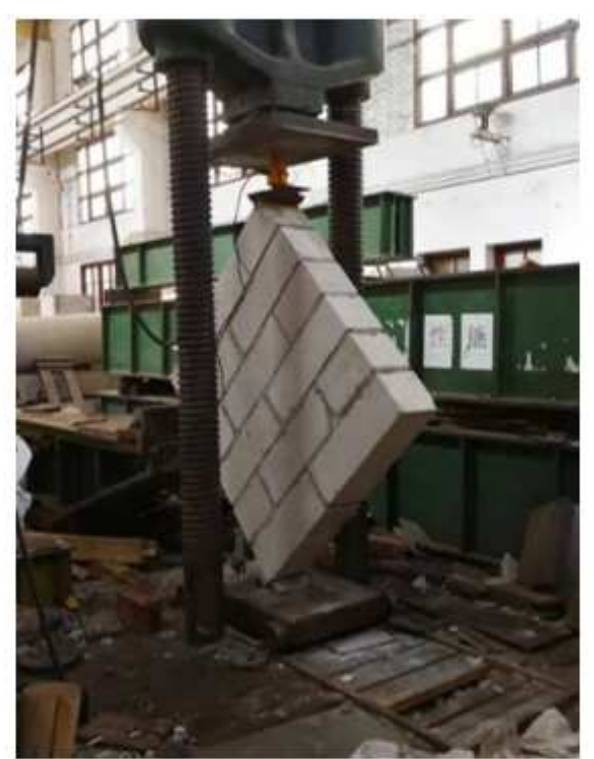

(a) Diagonal test of masonry prisms

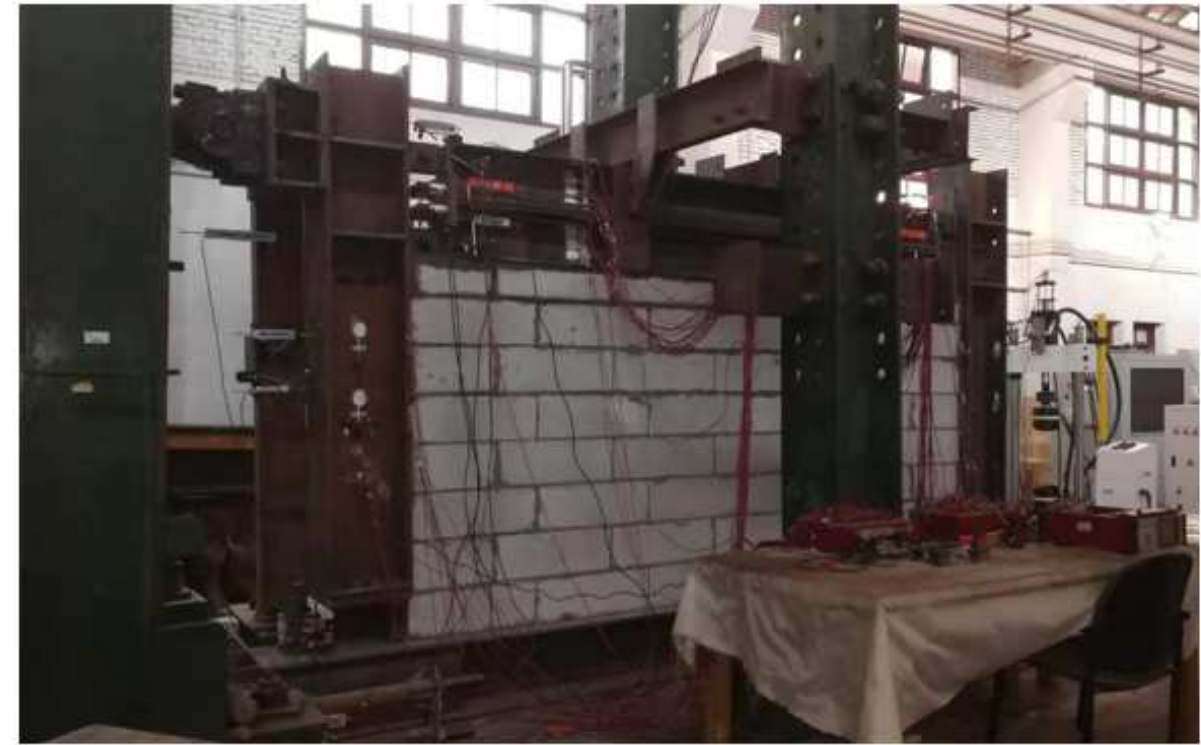

(b) Static cyclic test of infilled SCB-MF

Figure 10

Photograph of specimen and loading device
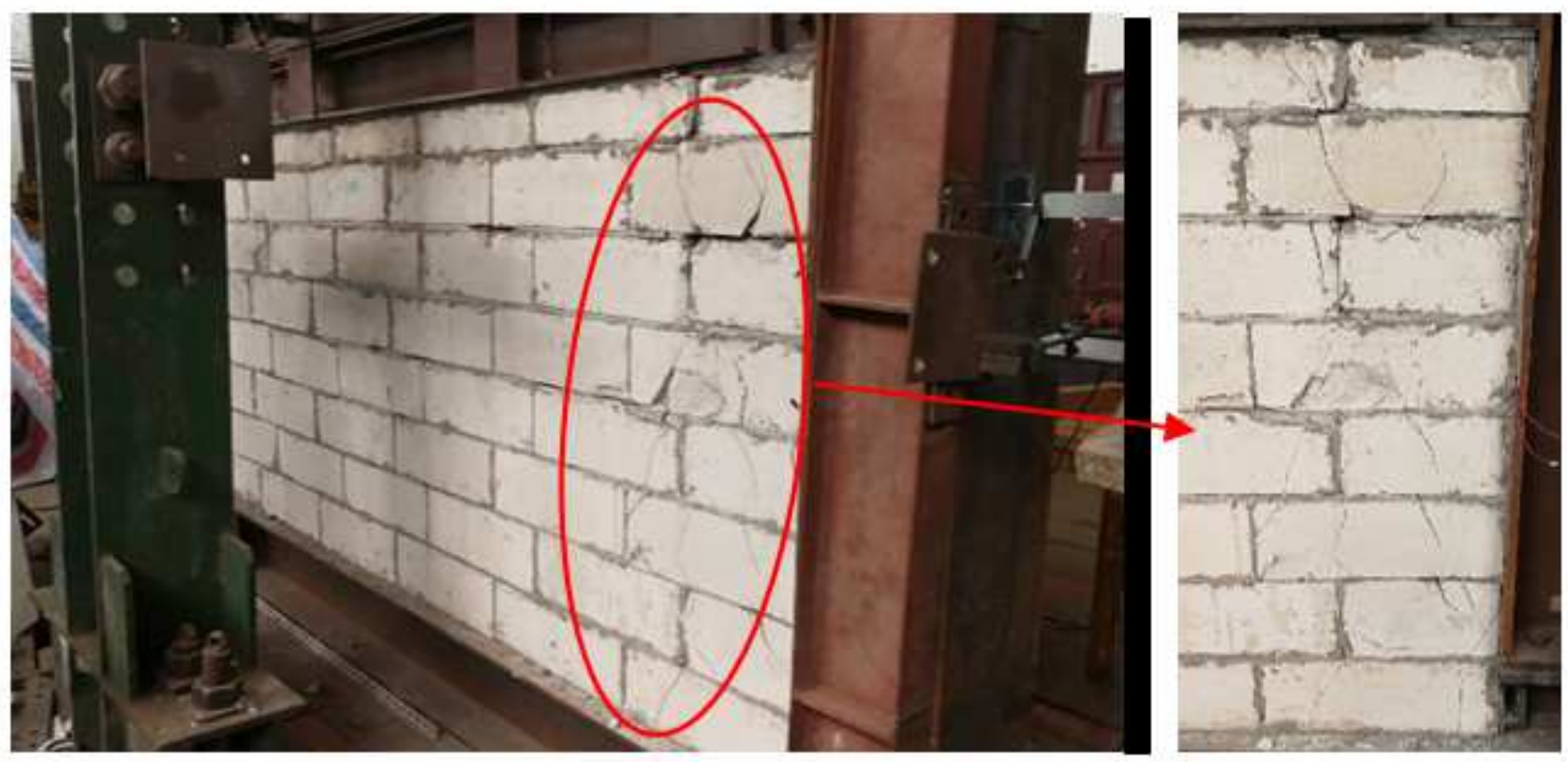

Figure 11

Crack propagation of infill wall after cyclic loading 

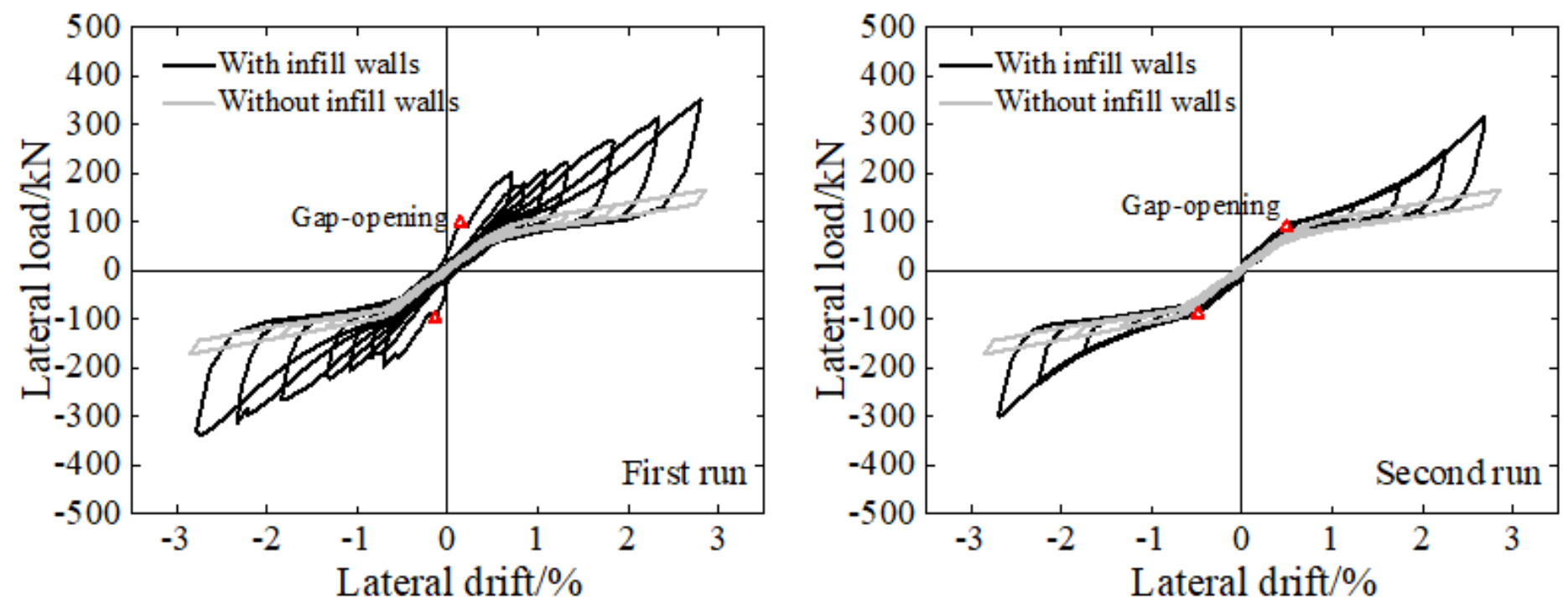

Figure 12

Hysteretic responses of SCB-MFs with and without infill walls 

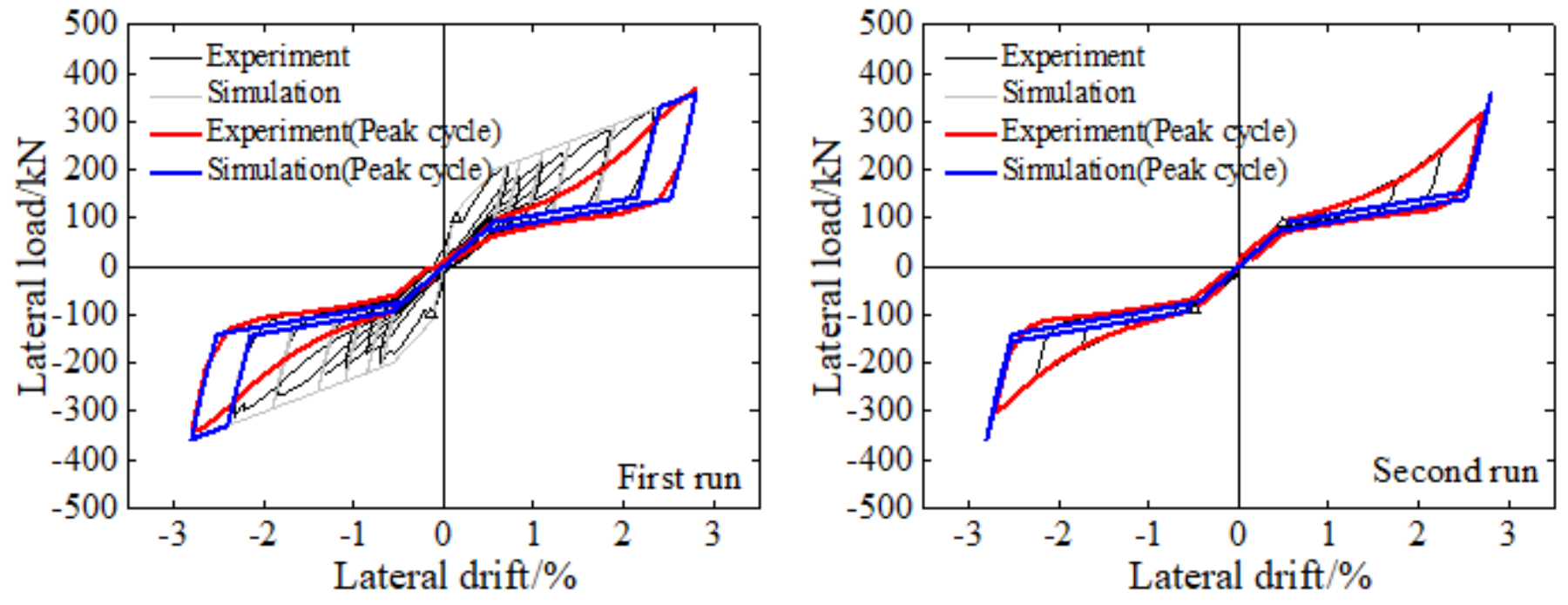

(a) Hysteretic+ENT
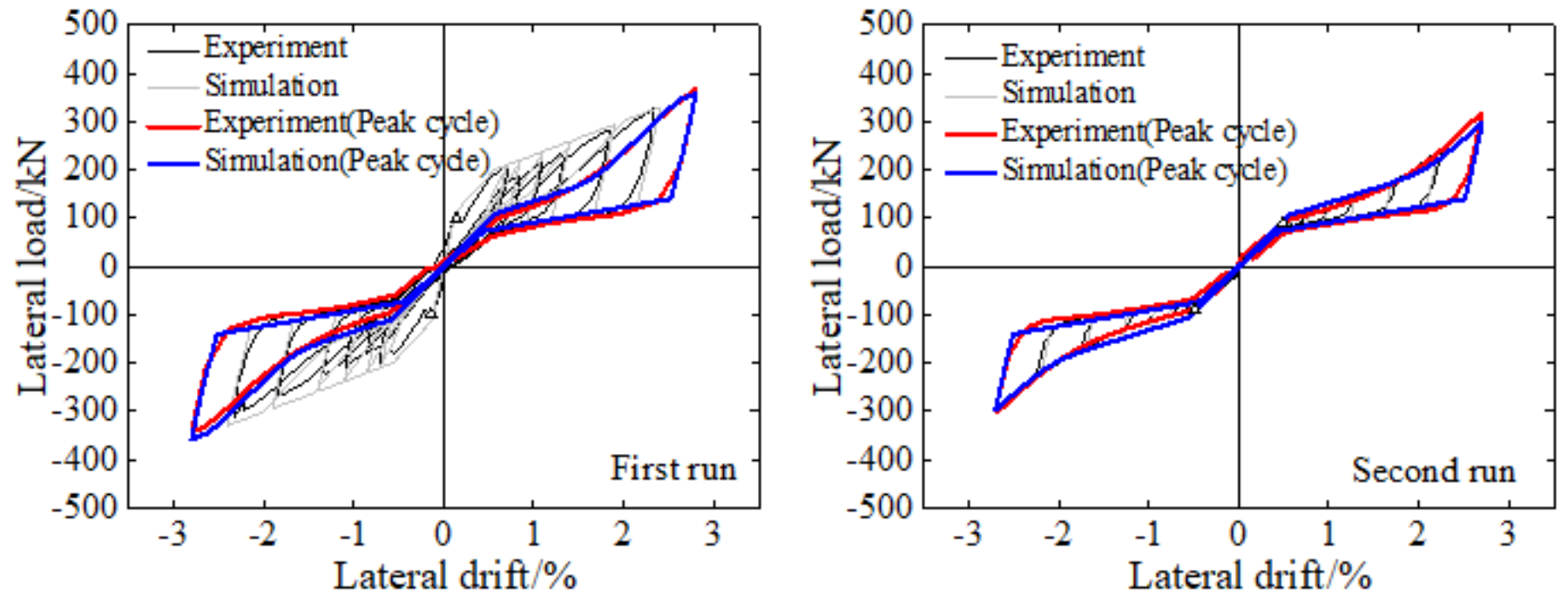

(b) Infillo1

Figure 13

Comparison of observed and experimental responses of infilled SCB-MF 


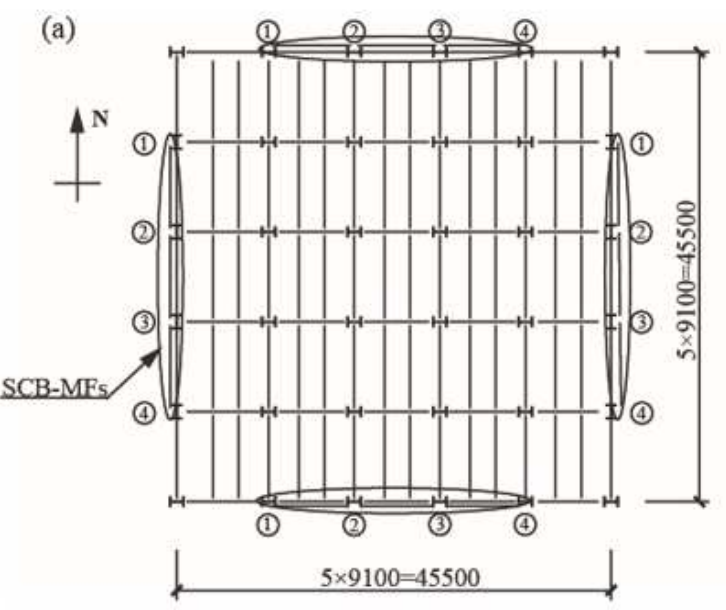

Gravity loads:

Roof: Dead $=3.0 \mathrm{kPa}$

Live $=1.0 \mathrm{kPa}$

Floor:Dead $=3.5 \mathrm{kPa}$

Partitions $=1.0 \mathrm{kPa}$

Live $=3.8 \mathrm{kPa}$

Exterior walls $=1.5 \mathrm{kPa}$

Seismic Load Data:

Van Nuys, Los Angeles

$\mathrm{Ss}=1.5 \mathrm{~g}, \mathrm{~S}_{1}=0.6 \mathrm{~g}$

Occupancy Category I

Importance Factor $=1.0$

Site Class D

$\mathrm{Fa}=1.0 ; \mathrm{Fv}=1.5$

$\mathrm{SDs}=1.0 \mathrm{~g} ; \mathrm{Sd}=0.6 \mathrm{~g}$

(b)

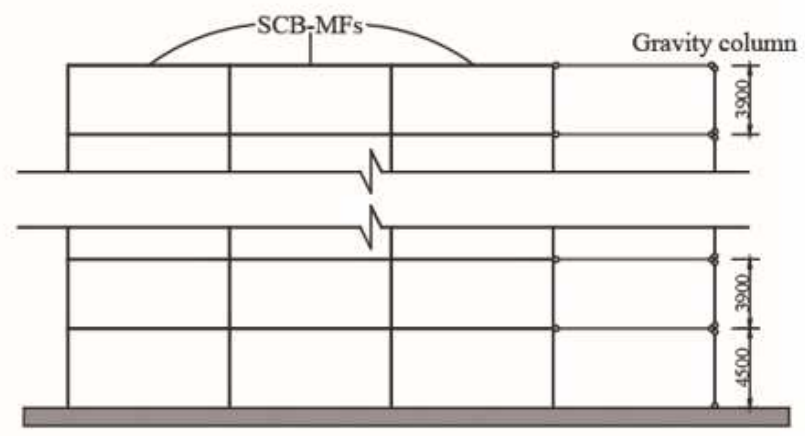

Figure 14

(a) Plan of prototype building, and (b) elevation of prototype frame

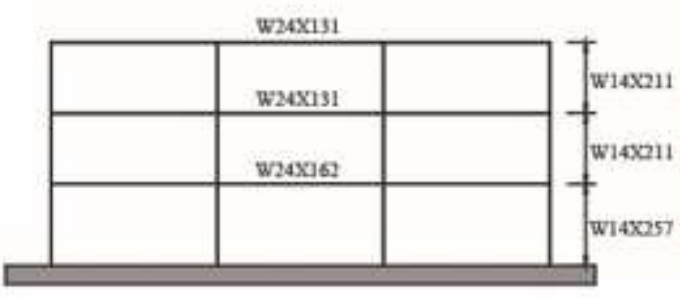

(a) 3-storey prototype

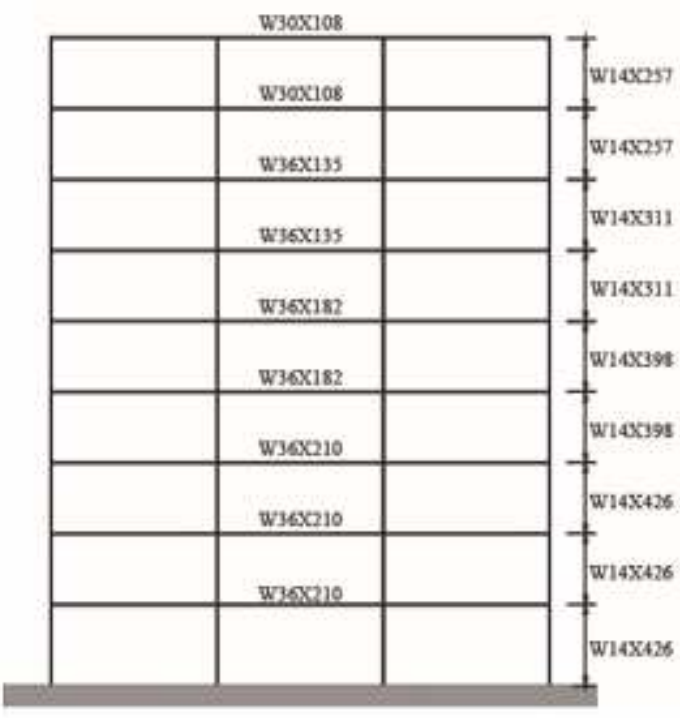

(c) 9-storey prototype

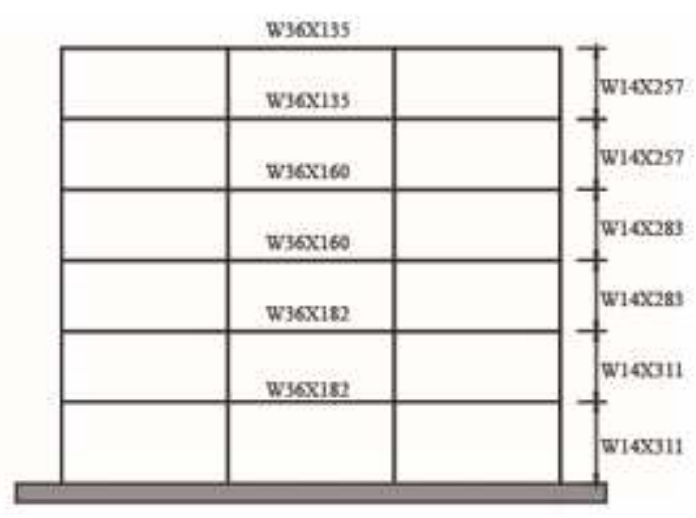

(b) 6-storey prototype

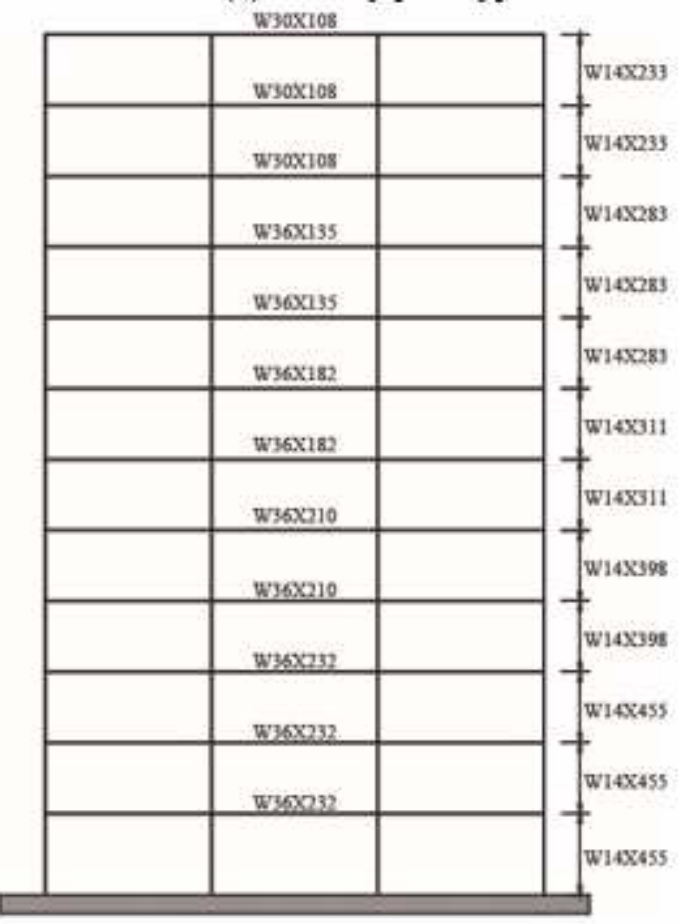

(d) 12-storey prototype 
Figure 15

Beam and column sections of SCB-MFs with different numbers of storeys
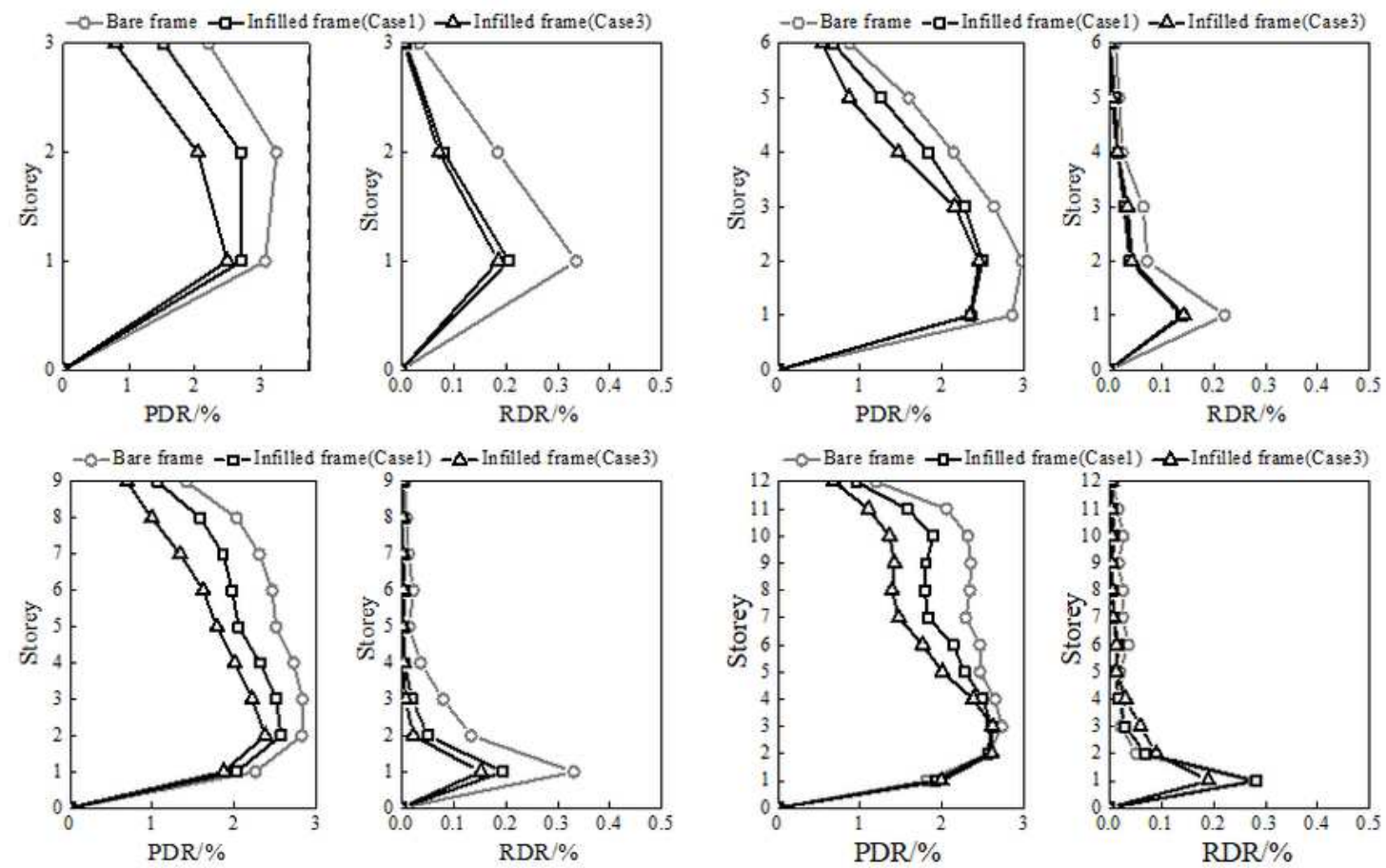

(a) AAC masonry
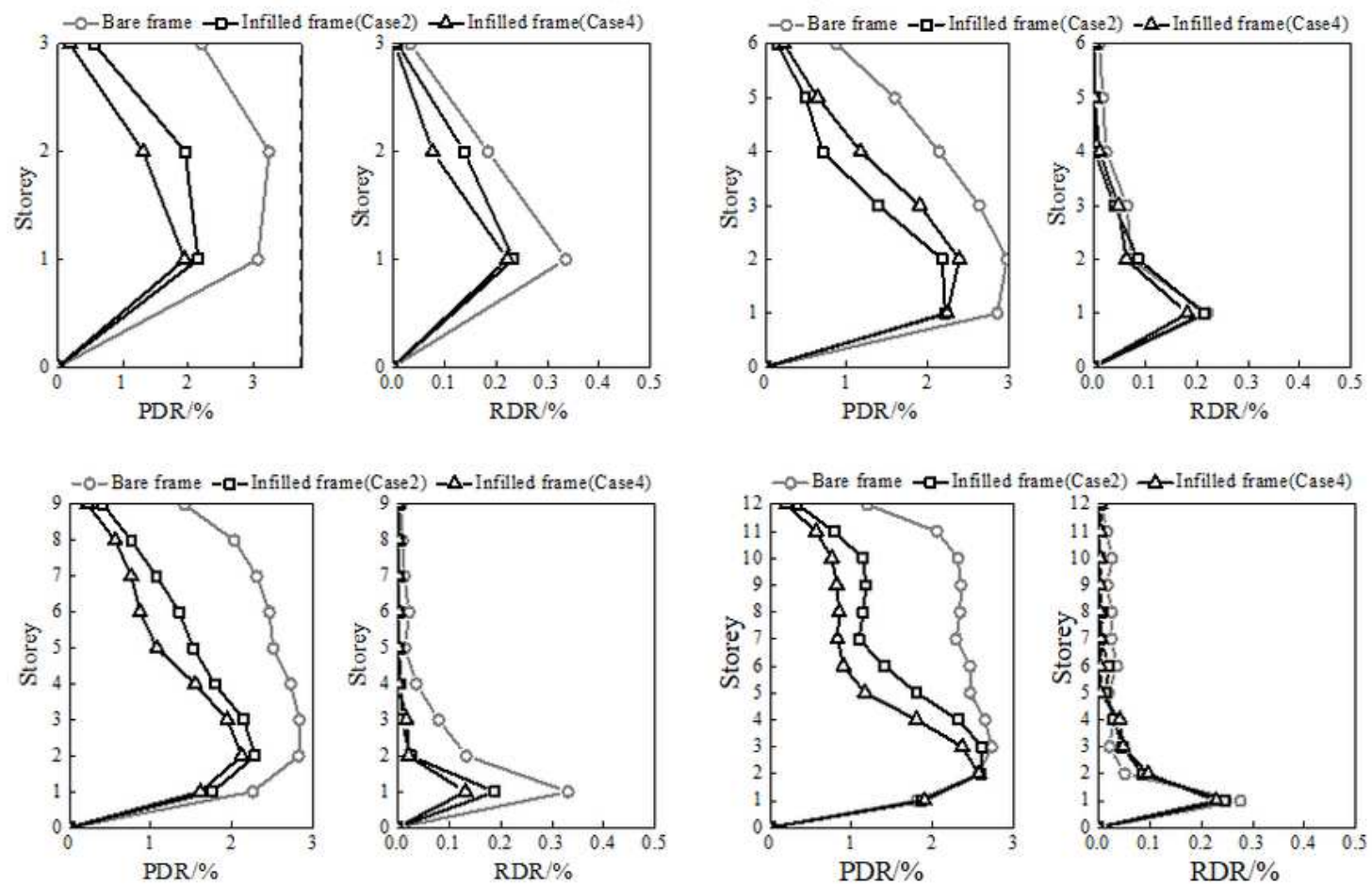

(b) PC masonry

\section{Figure 16}

Statistics for seismic responses in relation to height for SCB-MFs with and without infill walls under MCEs 


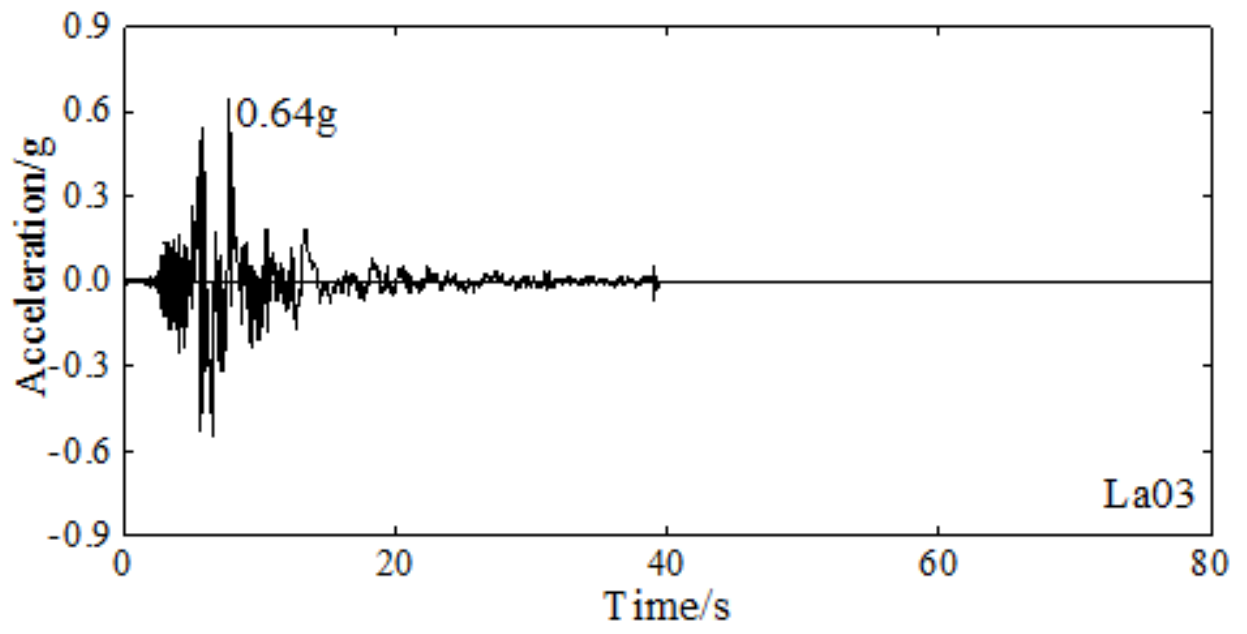

Figure 17

Acceleration time histories of scaled $\mathrm{LaO3}$ record at MCE level 

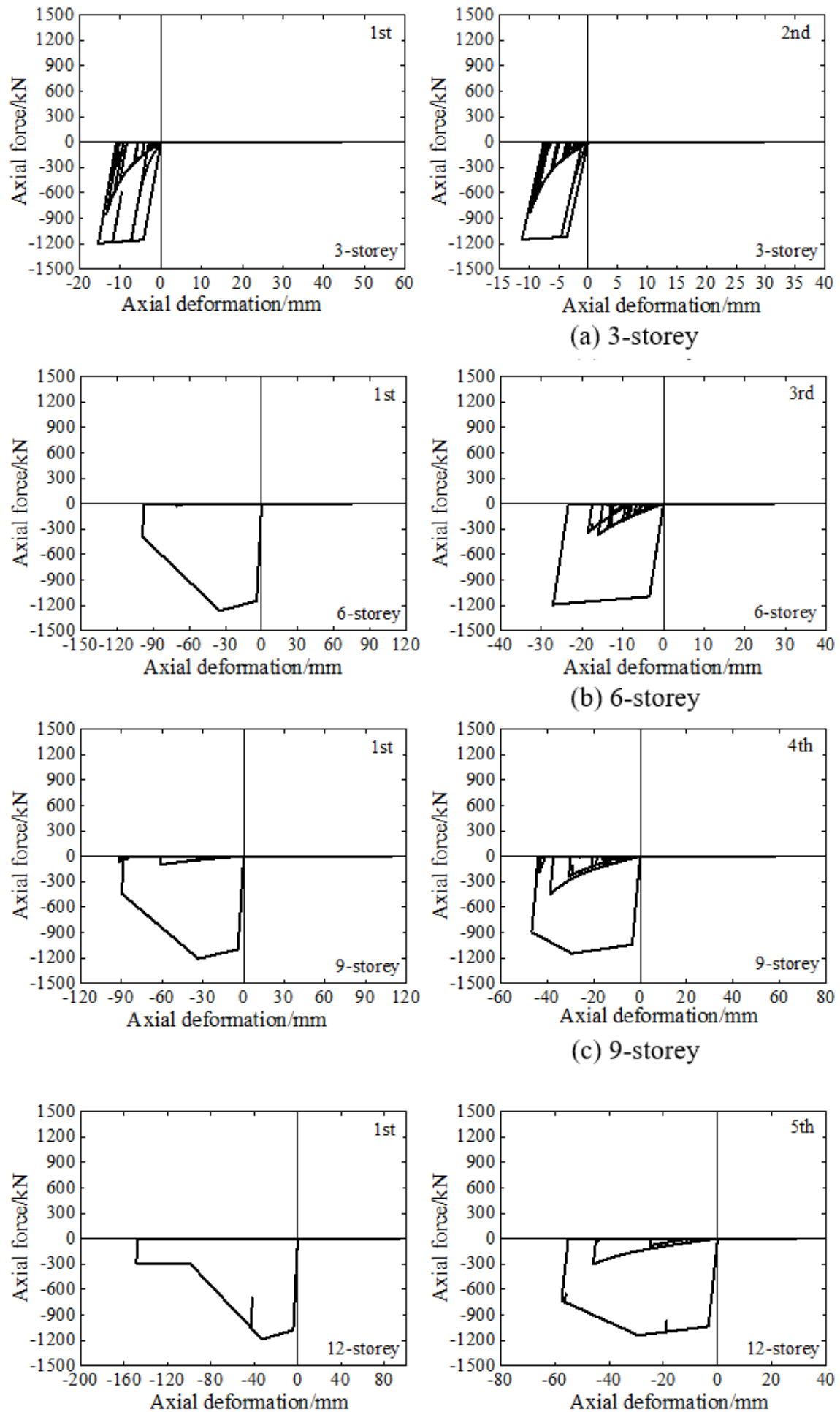

(a) 3-storey

(b) 6-storey

(c) 9-storey
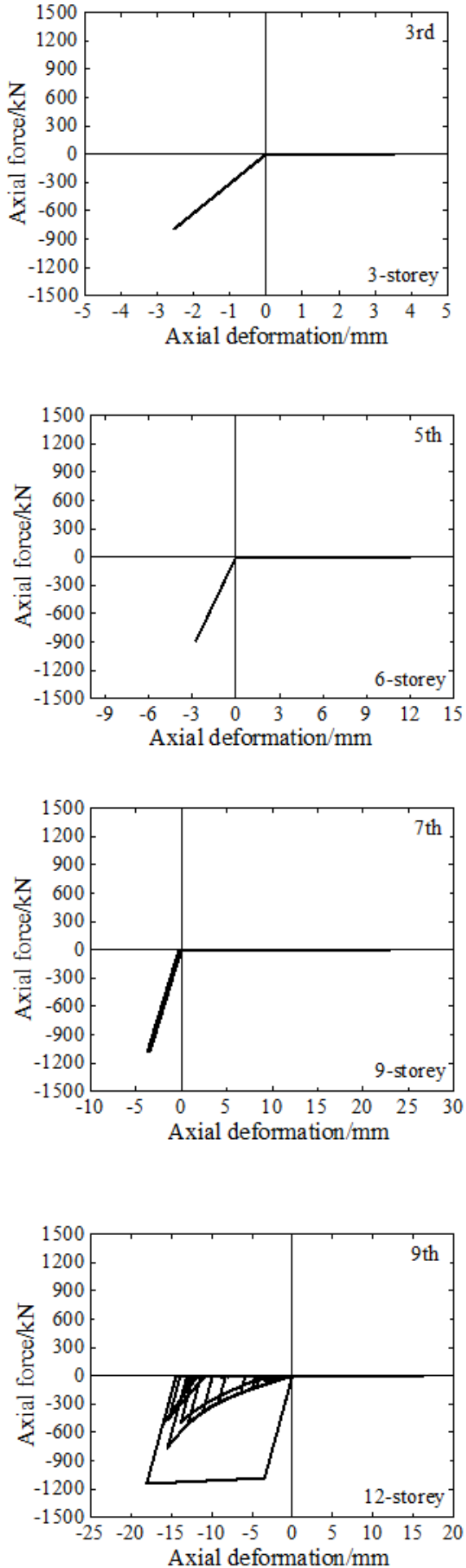

(d) 12-storey

\section{Figure 18}

Hysteretic responses of equivalent struts for masonry infill walls at various storeys under La03 motion 